\title{
MesoLAPS Predictions of Low-Level Convergence Lines over Northeastern Australia
}

\author{
BERNADETT WEINZIERL \\ Institut für Physik der Atmosphäre, Deutsches Zentrum für Luft- und Raumfahrt, Oberpfaffenhofen, Germany
}

ROGER K. SMITH

Meteorological Institute, University of Munich, Munich, Germany

Michael J. ReEder

Centre for Dynamical Meteorology and Oceanography, Monash University, Clayton, Victoria, Australia

\author{
GORDON E. JACKSON
}

Bureau of Meteorology, Darwin, Northern Territory, Australia

(Manuscript received 13 April 2006, in final form 11 October 2006)

\begin{abstract}
The prediction of low-level convergence lines over northeastern Australia such as those which give rise to the "morning glory" phenomenon and the north Australian cloud line (NACL) are investigated using MesoLAPS, a mesoscale version of the Australian Bureau of Meteorology's operational Limited Area Prediction System. The model is used also to examine aspects of the dynamics of such lines. The predictions were made during the Gulf Lines Experiment in 2002 and are compared here with data collected during the experiment. The ability of MesoLAPS to forecast the convergence lines is investigated in detail for selected cases. In two cases with well-developed southerly morning glory disturbances, the model was able to capture the separation of a borelike disturbance from an airmass change, although the model does not have the resolution to capture the wavelike structures that develop at the leading edge of the bore waves. An analysis of the entire 44-day period between 11 September and 24 October shows that MesoLAPS has significant skill in forecasting the lines, but it does not capture all of them. About $85 \%$ of forecasts of northeasterly morning glories and southerly morning glories, or of their nonoccurrence, were correct, while the corresponding percentage for the NACL was about $65 \%$. However, about $15 \%$ of northeasterly morning glories and about $35 \%$ of NACL events that occurred were not forecast by the model. Also, only 6 out of 11 southerly morning glories were forecast. A detailed analysis of the MesoLAPS calculations indicates that the broad-scale generation mechanisms of northeasterly and southerly morning glories are similar and it enables the construction of a conceptual model for the generation of southerly morning glories.
\end{abstract}

\section{Introduction}

An important, but difficult, forecasting problem in northern Australia is to predict the occurrence of deep convection. Frequently, convective storms are triggered along convergence lines that originate as a result of organized mesoscale circulations such as sea breezes. If

Corresponding author address: Prof. Roger K. Smith, Meteorological Institute, University of Munich, Theresienstr. 37, 80333 Munich, Germany.

E-mail: roger@meteo.physik.uni-muenchen.de one can forecast these lines, it might be possible also to forecast the storms that they initiate.

The Gulf of Carpentaria ${ }^{1}$ and Cape York Peninsula region of northeastern Australia is well known for the regular occurrence there of two main types of cloud lines that are associated with mesoscale convergence lines. One type is the "morning glory" phenomenon, a spectacular traveling wave cloud system commonly observed over the southern part of the gulf and adjacent seaboard, and the other is the north Australian cloud

\footnotetext{
${ }^{1}$ See Fig. 1 for places mentioned in the text.
} 
line (NACL), or "gulf line," a line of convective cloud that is seen in satellite imagery to extend frequently across the entire gulf. During the dry season (AprilOctober), gulf lines are relatively shallow and generally do not produce rain, but during the transition and wet seasons (November-March) they may develop into thunderstorms with severe wind squalls and heavy rain showers. The latter type of cloud line is of particular interest to forecasters because thunderstorms are intrinsically difficult to predict and these lines of storms can affect large regions of northern Australia including the "Top End" of Australia, the region west of the gulf.

The NACL and the majority of morning glories form near the western side of the peninsula when there is a moderate (typically $5 \mathrm{~m} \mathrm{~s}^{-1}$ ) low-level easterly airflow across the peninsula. Especially favorable is a ridge of high pressure along the east coast of Australia, which enhances the easterlies (Clarke et al. 1981). Subsequently, the cloud lines move with a westward component across the gulf. The morning glory is accompanied by sudden wind squalls, intense low-altitude wind shear, and a marked vertical displacement of air parcels, sometimes sufficient to initiate showers or thunderstorms in the wake of the disturbance. A few morning glory-type disturbances originate south of the gulf and move northward. We refer to these as "southerly morning glories," or "southerly wind surges," to distinguish them from the more common ones that normally move from the northeast. The latter terminology was preferred by Smith et al. (1986) as it emphasizes the sharp wind change that accompanies the disturbance and not all disturbances form cloud lines.

The NACL brings about a low-level wind change also (Goler et al. 2006). During the dry season the depth of convection is generally limited by a trade wind inversion at a height of about $3 \mathrm{~km}$, but at other times, showers and thunderstorms may develop when the air over the gulf is sufficiently unstable. A recent review of these phenomena and a comprehensive set of references is given by Reeder and Smith (1998).

There is now ample evidence that the northeasterly morning glories and the NACL have their origin in organized mesoscale circulations that develop over the peninsula and adjacent gulf associated with sea breezes (Clarke et al. 1981; Clarke 1984; Noonan and Smith 1986, 1987; Drosdowsky et al. 1987; Smith and Noonan 1998; Goler and Reeder 2004; Thomsen and Smith 2006).

Some insight into the generation of the convergence lines that accompany northeasterly morning glories and the NACL was provided by the idealized numerical studies of sea-breeze circulations over Cape York Peninsula by Noonan and Smith (1987) and Smith and
Noonan (1998). The results of these studies raised the possibility that the convergence lines could be forecasted using operational numerical models. This possibility was explored by Jackson et al. (2002), who used MesoLAPS, the mesoscale version of the Australian Bureau of Meteorology's Limited Area Prediction System (LAPS), to forecast the convergence lines that form in the gulf region on a few occasions when prominent cloud lines were seen in satellite imagery. However, the only way to verify the forecasts was to assume that observed cloud lines mark the position of the convergence line in reality.

The majority of southerly morning glory convergence lines appear to be associated with ridging across central and northeastern Australia and the presence of an inland trough just south of the gulf (Smith et al. 1986, 1995; Reeder et al. 2000; Smith et al. 2006; see also below). The possibility of forecasting these lines has not been investigated previously.

Because of the importance of being able to forecast the convergence lines in the region, and in the Tropics in general, the Gulf Lines Experiment (GLEX) was carried out during September-October 2002, with one of its primary aims being to gather the necessary data to verify the MesoLAPS forecasts. Observations of selected NACL events made during the experiment are described in a paper by Goler et al. (2006) and details of the southerly morning glories documented are given by Smith et al. (2006). The present paper summarizes all events observed during GLEX, focusing on the ability of the MesoLAPS forecasts made during GLEX to capture the various convergence lines that were observed, including those associated with southerly morning glories. The predictions of three interesting events are examined in detail.

A further aim of the paper is to use diagnostics of these forecasts to better understand the mechanisms involved in the generation of the convergence lines, especially those moving from the south. The analysis of MesoLAPS forecasts together with the findings from GLEX are synthesized into a dynamically consistent conceptual model describing the generation of southerly morning glories. The conceptual model provides an aid in the interpretation of the numerical forecasts and forms a basis for forecasting southerly wind surges in the gulf region.

The paper is organized as follows. In section 2 we describe briefly MesoLAPS and the real-time forecasts that were provided for GLEX. In section 3 we examine three events in detail and follow in section 4 with a summary of the predictions for all events. In section 5 we show that the generation mechanism for southerly morning glories is very similar to that for northeasterly 
morning glories and in section 6 we propose a conceptual model for the generation of southerly disturbances. The conclusions are given in section 7 .

\section{LAPS and MesoLAPS}

The numerical model and data assimilation system that constitute LAPS are described by Puri et al. (1998). The prognostic model is hydrostatic and solves the primitive equations on a nonstaggered, latitudelongitude, Arakawa A grid with $\sigma=p / p_{s}$ as the vertical coordinate, where $p$ is the pressure and $p_{s}$ the surface pressure. The horizontal momentum equations use fourth-order spatial differencing to calculate the pressure gradient and geopotential gradient terms. The initial conditions and boundary conditions are taken from the Australian Bureau of Meteorology's Global Analysis and Prediction (GASP) system, which is based on a spectral model with a horizontal resolution of approximately $85 \mathrm{~km}$. LAPS performs calculations over a domain that extends from $65^{\circ} \mathrm{S}$ to $15^{\circ} \mathrm{N}$ and from $65^{\circ}$ to $185^{\circ} \mathrm{E}$

MesoLAPS is merely a high-resolution version of LAPS with the same physics. It has a horizontal grid spacing of $0.125^{\circ}$ (about $12 \mathrm{~km}$ ) and 29 levels in the vertical with finer resolution in the boundary layer. The approximate heights of the sigma levels below $3 \mathrm{~km}$ are $10 \mathrm{~m}(\sigma=0.9988)$ and $20,45,100,210,320,430,650$, $880,1050,1350,1800,2300$, and $2850 \mathrm{~m}$. The calculation domain covers the region from $22^{\circ}$ to $5.25^{\circ} \mathrm{S}$ and $125^{\circ}$ to $151.125^{\circ} \mathrm{E}$, corresponding to lengths of about $1800 \mathrm{~km}$ in the meridional direction and $2900 \mathrm{~km}$ in the zonal direction (see Fig. 1a). The model topography is derived from a $0.1^{\circ}$ resolution dataset as shown in Fig. 1 . The model obtains its initial and boundary conditions from LAPS at a $0.375^{\circ}$ horizontal resolution. The analysis is interpolated from the coarse-resolution LAPS analysis and does not show the level of detail available in the MesoLAPS forecasts. The forecasts described were carried out operationally for the GLEX experiment so that no data from the experiment could be used for the initialization. This has the added advantage that the forecasts are independent of the data used to verify them.

The surface fluxes of momentum, heat, and moisture are parameterized using the Monin-Obhukov formulation with a stability-dependent drag coefficient. The radiation scheme uses a combination of Lacis and Hansen's (1974) parameterization for solar wavelengths and the Fels and Schwarzkopf (1975) method for terrestrial wavelengths and is called each hour during the integration. The sea surface temperature (SST) dataset used is from the bureau's operational SST analysis scheme

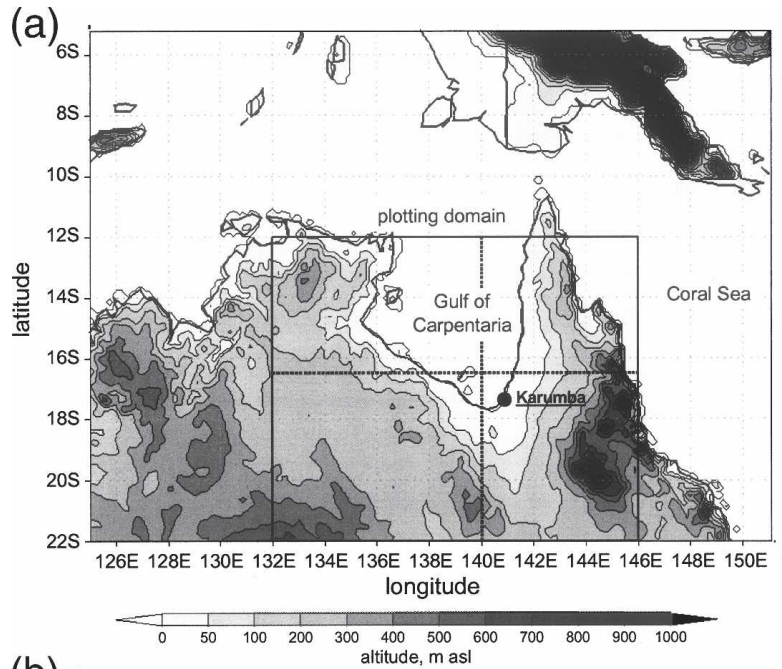

(b)

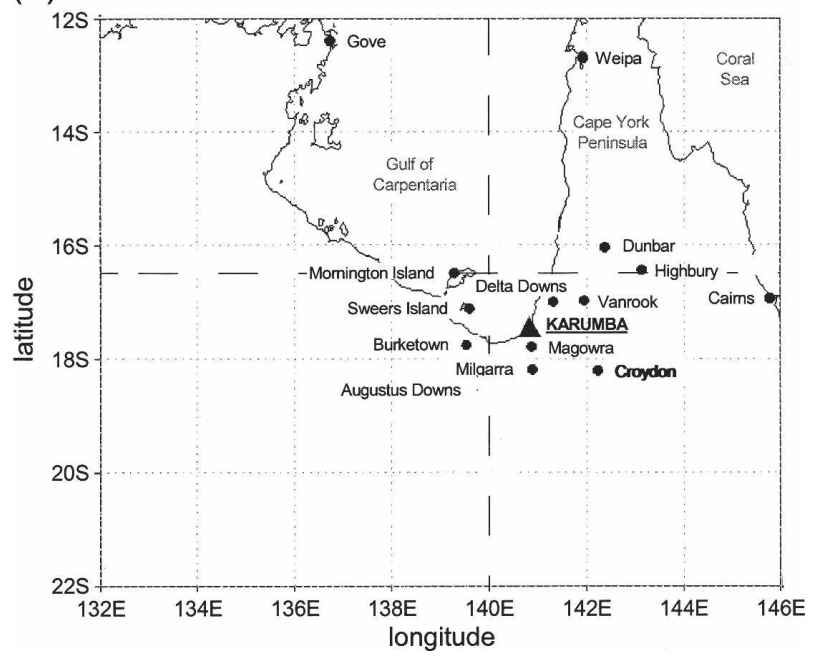

FIG. 1. (a) Topographic map of northern Australia and southern Papua New Guinea with the 100-, 250-, 500-, 1000-, 1500-, and 2000-m contours indicated; and (b) a detailed map of the Gulf of Carpentaria region with the location of the AWS network and the operation center at Karumba indicated. All AWSs are located in Queensland. In (b) the domain used for all subsequent horizontal plots is shown and the dashed lines mark the locations of the meridional and zonal vertical cross sections shown later.

(Smith 1995) at a $1^{\circ}$ resolution. A land surface scheme is used that provides a detailed vegetation and soil-type specification $\left(0.25^{\circ} \times 0.25^{\circ}\right.$ resolution $)$ with soil moisture values initialized daily based on rainfall observations and climatological surface evaporation rate estimates.

The output data are interpolated to pressure surfaces and are available at 3 -h intervals. The resolution of MesoLAPS is probably adequate to resolve the mesoscale environment in which the cloud lines form, including the sea-breeze circulations and convergence lines 
TABLE 1. List of MesoLAPS forecasts used for the case studies described in this paper. Times are in EST $=$ UTC $+10 \mathrm{~h}$.

\begin{tabular}{lr}
\hline \hline \multicolumn{1}{c}{ Period (EST) } & \multicolumn{1}{c}{$\begin{array}{c}\text { MesoLAPS forecast } \\
\text { initialization date and time }\end{array}$} \\
\hline Event 1: 28-29 Sep 2002 & 28 Sep 2002, 1000 EST $+36 \mathrm{~h}$ \\
Event 2: 4 Oct 2002 & 3 Oct 2002, 1000 EST $+36 \mathrm{~h}$ \\
Event 3: 8-9 Oct 2002 & 8 Oct 2002, 1000 EST $+36 \mathrm{~h}$ \\
\hline
\end{tabular}

that develop, although the details of the sea-breeze fronts, the morning glory bore waves that may accompany the convergence lines, and the wave clouds themselves cannot be resolved. Another potential limitation of the model in this respect is the relatively high horizontal diffusion that is implemented to keep it stable in all operational situations (G. Dietachmayer 2006, personal communication).

\section{Case studies}

This section presents case studies of three of the most interesting events during GLEX, those of 28-29 September, and 4 and 9 October 2002, the observations of which are described in detail in Goler et al. (2006) and Smith et al. (2006). The disturbances over the southeastern part of the gulf were documented by satellite imagery, surface data (i.e., wind speed and direction, pressure, temperature, and humidity), and radar data. For the event of 9 October, data were also acquired from an instrumented research aircraft, and a few pilot balloon and radiosonde soundings were made at Karumba. We examine below the ability of the MesoLAPS forecasts detailed in Table 1 to capture the convergence lines in these three cases.

\section{a. Event 1: 28-29 September 2002}

This event consisted of two convergence lines moving from the south and a line over Cape York Peninsula moving from the northeast that was observed only at Highbury and Dunbar. The leading line of those from the south had an undular bore-like structure characteristic of a morning glory, but we do not know if it was accompanied by wave clouds as it passed through our instrument network overnight (such clouds are difficult to detect in the infrared satellite imagery). The second line that followed some hours later brought a significant airmass change, which had the character of a dryline at the surface; that is, it was accompanied by a sharp drop in dewpoint temperature, but produced little change in surface temperature, or even a slight rise. MesoLAPS forecasts to be described indicate that it had the form of a shallow cold front above the surface layer, with a steady decline in temperature. It is unusual to observe a surface temperature fall with the passage of cold fronts over central and northern Australia at night; generally, one observes a temperature rise as a result of the downward mixing of potentially warm air across a strong, but relatively shallow, surface-based inversion (see, e.g., Smith et al. 1995, p. 23).

The northward-moving lines in this case are of particular interest because the leading borelike line was separating from the airmass change, suggesting that these lines were at some time a single disturbance. Moreover, the event is to our knowledge one of the best documented events of its type.

At the analysis time for the model forecast, 1000 eastern standard time (EST) 28 September, the synoptic situation was characterized by a ridge of high pressure along the northeast coast of Queensland and a ridge of high pressure extending northeastward across central Australia and northwestern Queensland from an anticyclone centered just south of Western Australia (see Smith et al. 2006; Fig. 1). The corresponding lowlevel flow pattern has southeasterly winds over the Coral Sea, easterlies over Cape York Peninsula, and northeasterlies over the Gulf of Carpentaria. The analysis time is about $11 \mathrm{~h}$ prior to the passage of the borelike disturbance over the southernmost automatic weather station (AWS) at Augustus Downs.

The different stages of evolution of the various convergence lines are illustrated by the divergence and horizontal wind fields at the 995-hPa level (about $150 \mathrm{~m}$ above the surface) in Fig. 2 and by the potential temperature gradient at $950 \mathrm{hPa}$ and mean sea level pressure shown in Fig. 3. At 1600 EST (Fig. 2a) an approximately northwest-southeast-oriented convergence line between $18^{\circ}$ and $22^{\circ} \mathrm{S}$, west of $143^{\circ} \mathrm{E}$, separates northeasterly winds equatorward from strong southerlies to southwesterlies circulating around the ridge to the south. The strongest potential temperature gradients are located around the coastlines (Fig. 3a). Weaker gradients in the potential temperature are found in the ridge, with virtually no gradient in the heat trough, which separates the ridge from the relatively cool air over the gulf.

At 1900 EST (Figs. 2b and 3b), about $2 \mathrm{~h}$ before the disturbance passed over Augustus Downs, the sea breeze along the southern and eastern coastlines of the gulf is evident as an onshore flow with a strip of enhanced convergence and strong potential temperature gradient marking the sea-breeze front. Over the northern half of Cape York Peninsula, the strip of enhanced convergence and strong potential temperature gradient lies offshore, while over the southern half there is a 
(a)

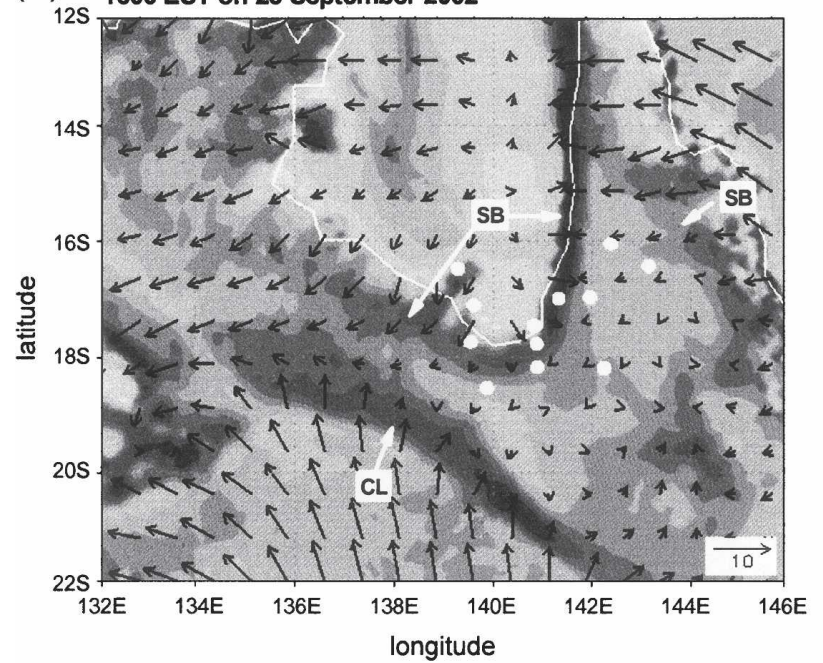

(c)

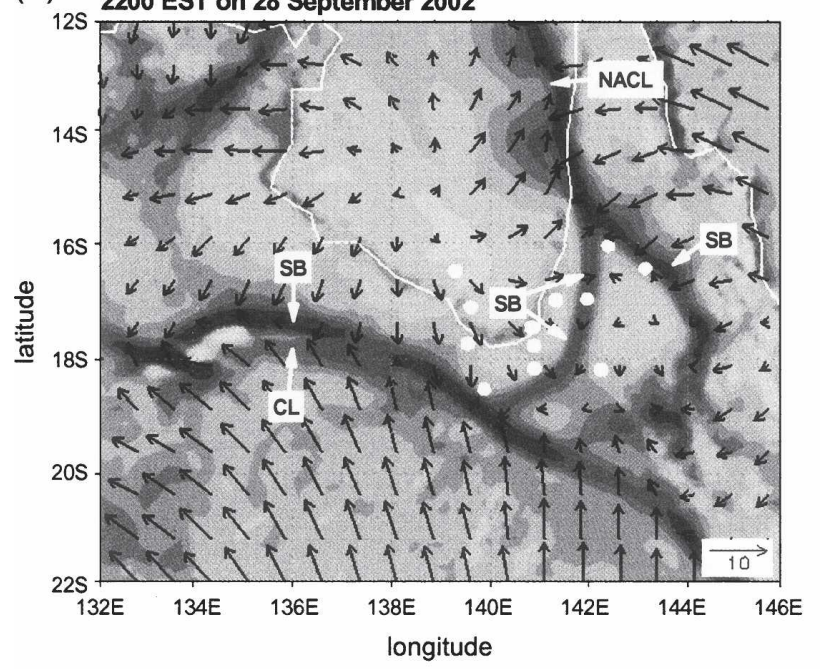

(b)

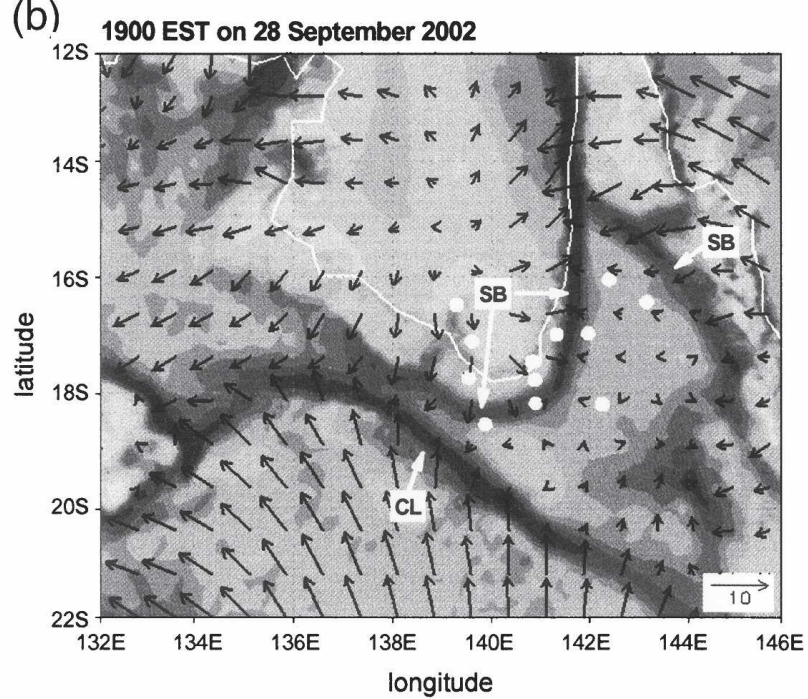

(d)

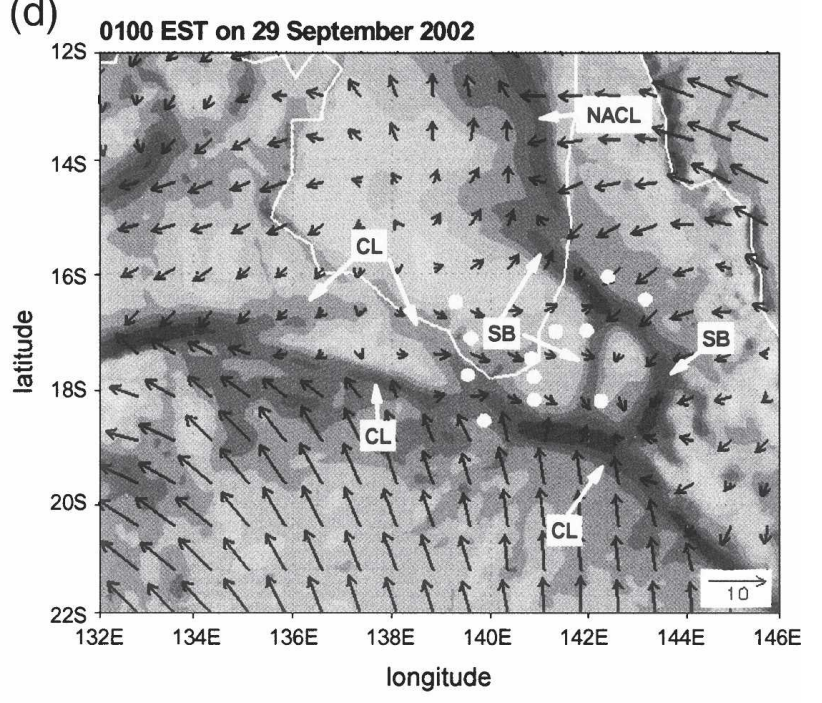

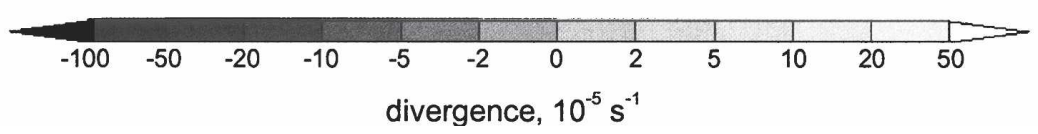

FIG. 2. MesoLAPS forecasts of mean sea level pressure (solid line, contour interval $1 \mathrm{hPa}$ ) and horizontal divergence (grayscale, $\times 10^{-5} \mathrm{~s}^{-1}$ ) and wind vectors at $995 \mathrm{hPa}$ at (a) 1600, (b) 1900, and (c) 2200 EST $28 \mathrm{Sep}$, and (d) 0100 EST 29 Sep. The wind speed is proportional to the length of the arrows. The arrow in the lower-right corner of each panel corresponds to $10 \mathrm{~m} \mathrm{~s}^{-1}$. The white dots mark the position of the AWSs. The convergence line corresponding to the cold front to the south of the gulf as well as [in (d)] that corresponding to the southerly morning glory are marked by CL. The sea-breeze convergence lines are indicated by SB and that corresponding to the north Australian cloud line by NACL.

strip extending northwest to southeast with strong northeasterly winds on the eastern side. The latter marks the front associated with the east coast sea breeze. South of the gulf, the sea-breeze front is very close to Augustus Downs at this time, consistent with the observed time of passage there just before 1900 EST. The observed time is based on the sharp increase in dewpoint temperature seen in the AWS data (see Smith et al. 2006; Fig. 2, left panel). The cold front is marked by a curved line of enhanced convergence south of the gulf. Strong frontogenesis has occurred along the northern perimeter of the ridge. The front that has formed has strong south-to-southeasterly winds on its southern side. Three hours later, at 2200 EST (Figs. 2c and 3c), the cold front had moved northward and merged with the sea-breeze front that was to its north. By 0100 EST (Figs. 2d and 3d) the convergence line marking the front had passed over Augustus 
(a)

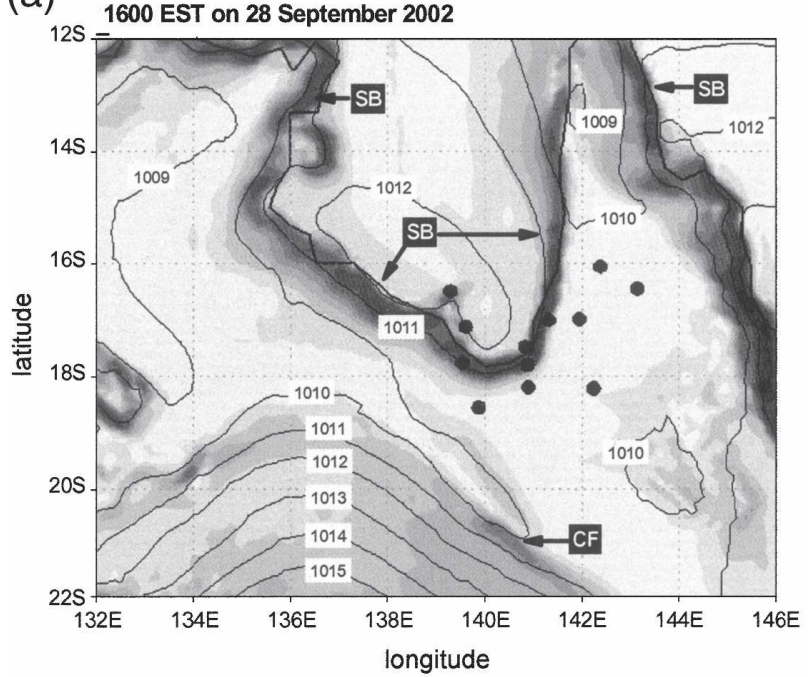

(c)

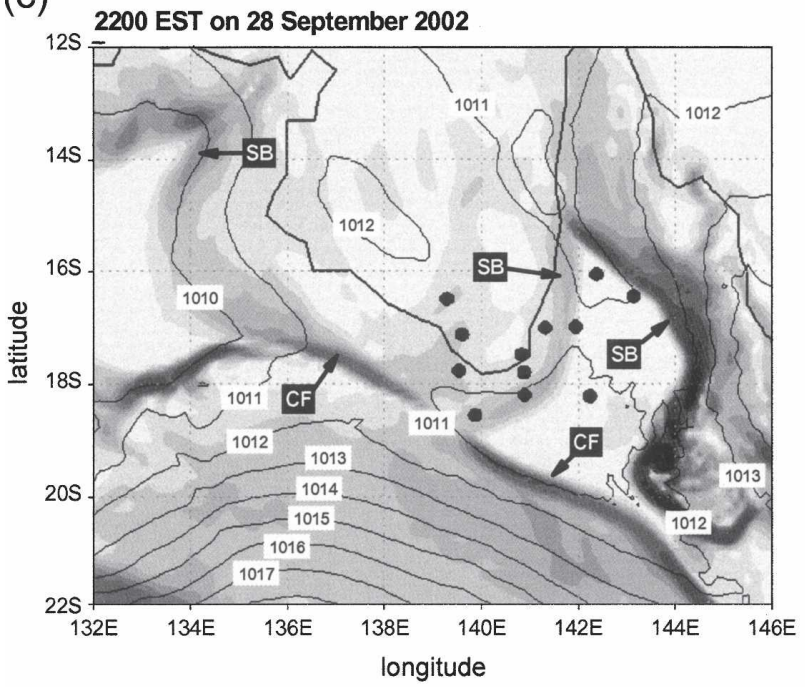

(b)

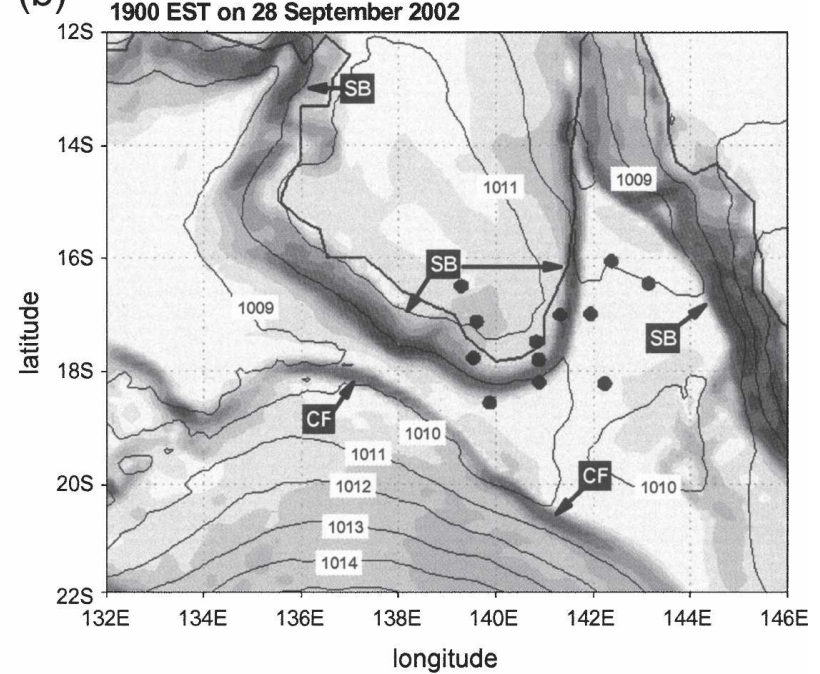

(d)
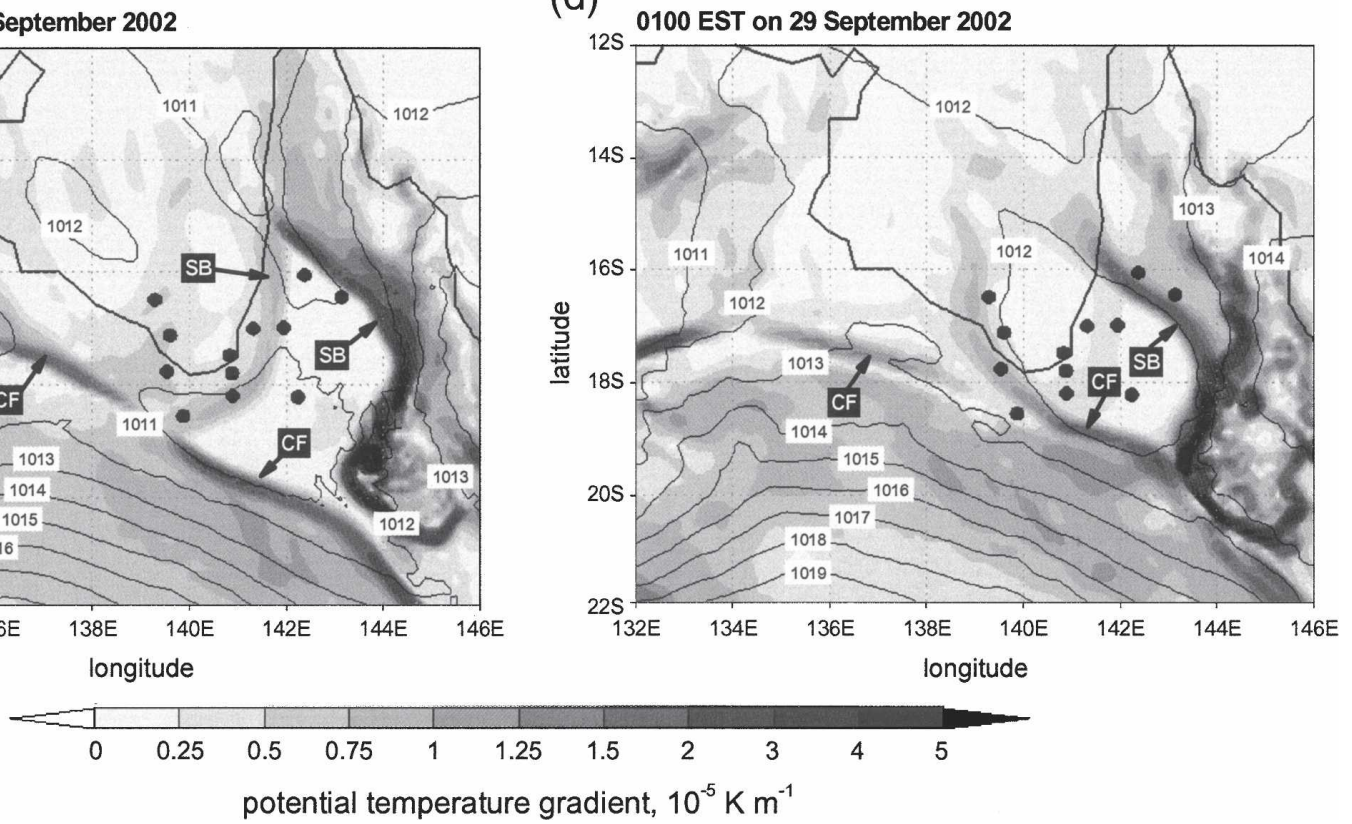

FIG. 3. MesoLAPS forecasts of potential temperature gradient (grayscale, $10^{-5} \mathrm{~K} \mathrm{~m}^{-1}$ ) at $950 \mathrm{hPa}$ at (a) $1600 \mathrm{EST} 28 \mathrm{Sep}$, and (b) 1900, (c) 2200, and (d) 0100 EST 29 Sep. The black dots mark the position of the AWSs. The strips of enhanced gradient corresponding to the cold front to the south of the gulf and those corresponding to the sea-breeze fronts are indicated by CF and SB, respectively.

Downs and lay just south of Milgarra, the second most southerly AWS station. West of Augustus Downs, between $135^{\circ}$ and $140^{\circ} \mathrm{E}$, a second convergence line has propagated ahead of the cold front into the cooler air advected onshore by the sea breeze. This line appears to be the MesoLAPS representation of the southerly morning glory. At 0400 EST (figure not shown), the front had moved farther north, as far as Karumba.

The times of passage of the leading convergence line in the model can be estimated at various AWS locations using the fact that its passage brings about a reversal of the meridional component of the near-surface wind, a feature of the observations also. These times are unambiguous and coincide closely with significant pressure jumps (typically $>1 \mathrm{hPa}$ in $5 \mathrm{~min}$ ). Using linear interpolation between MesoLAPS output times at 3-hourly intervals, the times of passage at AWS stations can be estimated to an accuracy of about $\pm 30 \mathrm{~min}$. The passage of the airmass change can be estimated to a similar accuracy by an analysis of sequences of meridional cross sections of the mixing ratio at the longitude of each AWS. At night the passage of cold fronts is 
marked at the surface principally by a change in the mixing ratio, although above the surface inversion the change is accompanied by a fall in the temperature. For simplicity we choose the location with the highest gradient in mixing ratio at $950 \mathrm{hPa}$ as the airmass change.

Between $135^{\circ}$ and $140^{\circ} \mathrm{E}$, the model produces two convergence lines as observed, while outside this longitude band only a single change is forecast. The model predicts the passage of the first line at Augustus Downs at 2230 EST 28 September compared with 2115 EST, and at Karumba around 0200 EST the next day compared with 0000 EST. The predicted times of passage of the airmass change at these stations are later than observed also: 0000 EST at Augustus Downs compared with 2245 EST, and 0400 EST at Karumba compared with 0225 EST. We consider these to be excellent forecasts.

Another prominent feature in Fig. 2 is the convergence line over the northeastern gulf that extends southeastward over the lower half of the peninsula and has strong northeasterly winds to the east of it. This line is seen to be translating southwestward and it corresponds to the precursor to a northeasterly morning glory. Such a disturbance was recorded by the AWSs at Highbury at 2150 EST and Dunbar at 2315 EST, but was not seen at stations farther south or west. The line was maintained in the MesoLAPS forecast at 0100 EST 29 September, when it lay close to Delta Downs and Vanrook Stations, but by the next forecast time at 0400 EST it had been overrun by the stronger southerly convergence line.

Figure 4 shows meridional-height cross sections of the virtual potential temperature and horizontal winds along $140^{\circ} \mathrm{E}$ from the MesoLAPS forecasts at the same times as in Figs. 2 and 3. At 1600 EST (Fig. 4a) the warmest air associated with inland heat trough lies between $19.5^{\circ}$ and $20.5^{\circ} \mathrm{S}$, and the low-level flow (at pressures above $960 \mathrm{mb}$ ) has a northerly component except at very low latitudes. A cold front lies in the southernmost part of the section and the leading edge of the sea breeze is located just inland from the coast. At 1900 EST (Fig. 4b) the inland heat trough lies between $19^{\circ}$ and $20^{\circ} \mathrm{S}$ and is characterized by the deepest mixed layer and highest temperatures. A cold front marks the northern boundary of the ridge. The winds below about $400 \mathrm{~m}$ (pressures $\gtrsim 970 \mathrm{hPa}$ ) are north-northeasterly to northeasterly just to the north of the trough. A comparison with the horizontal plots at this time (Figs. 2b and $3 b$ ) shows that these winds are associated with the sea breeze from the southern gulf coast. Three hours later, the front has edged northward (Fig. 4c). The southerly winds behind the front extend through a much deeper layer than the northerlies on the northern side of the trough. The temperature gradient is largest below $950 \mathrm{hPa}$ and larger to the north of the trough than to the south. The coolest air at low levels lies over the gulf. There is cold-air advection in the lowest $2 \mathrm{~km}$ (up to $800 \mathrm{hPa}$ ) on the southern side of the trough and through a shallower layer (below $500 \mathrm{~m}$ or $950 \mathrm{hPa}$ ) on the northern side. By 0100 EST 29 September (Fig. 4d), the warm air in the trough (virtual potential temperatures greater than $306 \mathrm{~K}$ ) has become elevated above the surface as the sea breeze from the north and the cold front from the south meet. At this time the cold front is masked at the surface by the shallow nocturnal stable layer that forms. Consequently, there is little sign of its passage in the surface temperature.

Figure 5 shows the corresponding plots of the water vapor mixing ratio. At 1600 EST 28 September (Fig. $5 \mathrm{a})$, a marked moisture gradient is evident near $18^{\circ} \mathrm{S}$. This strong gradient marks the sea-breeze front from the southern gulf coast. The gradient moves southward as the sea breeze propagates inland (Fig. 5b), eventually sharpening and slowing as it encounters the cold front at the edge of the northward-expanding ridge (Fig. 5c). The gradient then begins to move northward and sharpens further as the cold front pushes northward (Fig. 5d). At this time, the strongest gradient in the water vapor mixing ratio coincides with the cold front aloft, and its passage corresponds to the passage of the dryline recorded at the AWS stations. These forecasts indicate that the dryline south of the gulf marks the maximum inland penetration of the sea breeze.

\section{b. Event 2: 4 October 2002}

The Japanese Geostationary Meteorological Satellite (GMS) visible image at 0632 EST 4 October (Fig. 6a) shows three disturbances. The first is a northeasterly morning glory oriented northeast-southwest with many cloud lines over the southeastern part of the gulf. The second is an NACL oriented almost north-south to the northeast of the northeasterly morning glory. The third is a southerly disturbance oriented east-west stretching several hundred kilometers to the west of the southernmost tip of the gulf.

Figure $6 \mathrm{~b}$ shows the horizontal divergence and wind vectors at $995 \mathrm{hPa}$ at $0700 \mathrm{EST} 4$ October, about half an hour after the time of the satellite image. The model produces four significant bands of convergence in the gulf region. The first of these bands lies over the water, extending southward to about $15^{\circ} \mathrm{S}$. The northern part is oriented almost north-south and corresponds to the NACL. The position of the predicted line at 2100 EST 
(a)

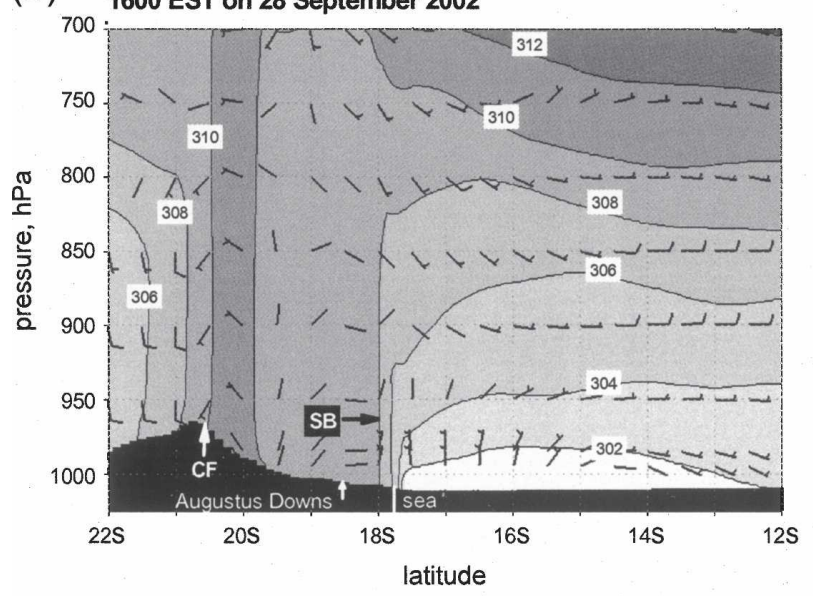

(c)

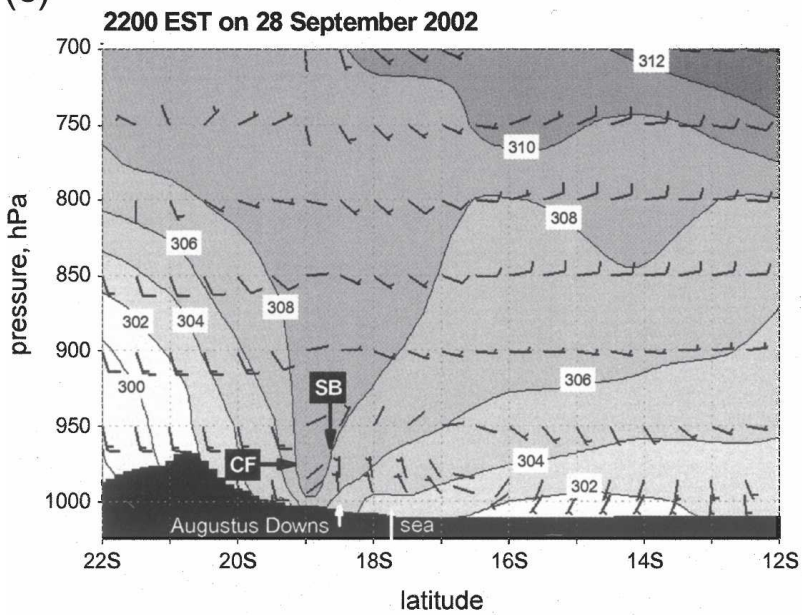

(b)

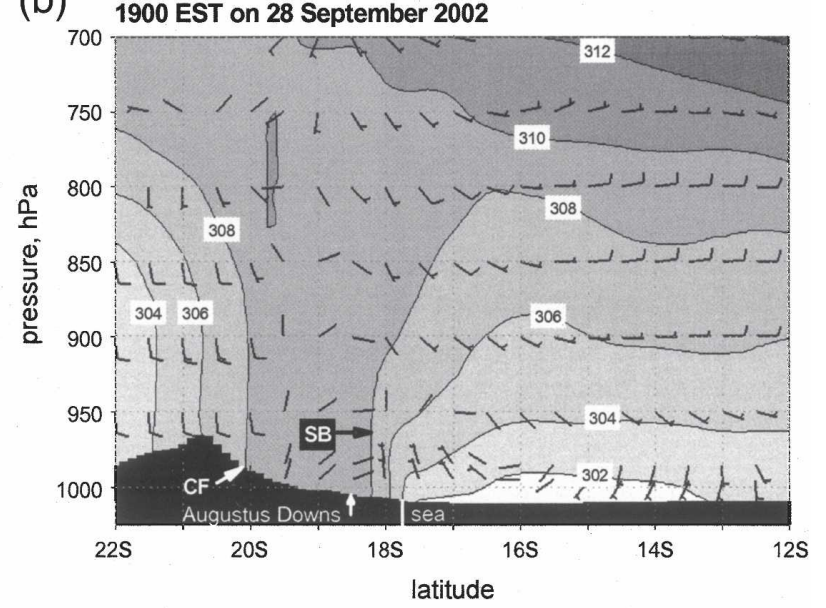

(d)

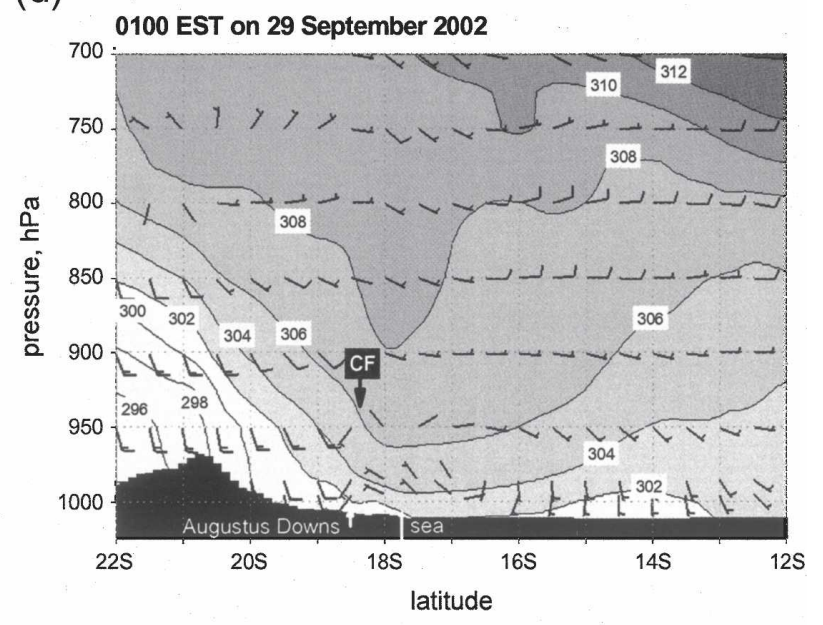

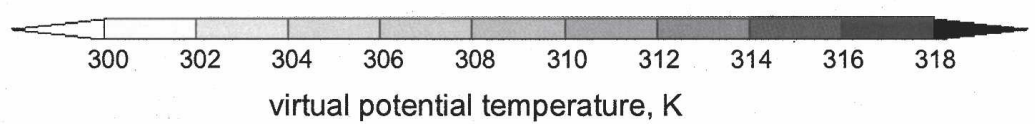

FIG. 4. Meridional cross sections along $140^{\circ} \mathrm{E}$ of the virtual potential temperature (grayscale, $\mathrm{K}$ ) and the horizontal wind (wind barbs) from the MesoLAPS forecasts for the southerly disturbance on 28-29 Sep. The forecasts are valid at (a) 1600 EST 28 Sep, and (b) 1900 , (c) 2200, and (d) 0100 EST 29 Sep. The vertical white line just north of $18^{\circ} \mathrm{S}$ on the abscissa marks the coastline. The arrow marks the location of Augustus Downs. The positions of the cold front and sea-breeze front to the south of the gulf are marked by CF and SB, respectively. In (d) the sea breeze has been overrun by the cold front and can no longer be identified.

is close to that of the NACL in the satellite image at 2030 EST and the orientation is the same $\left(172^{\circ} \pm 5^{\circ}\right) .^{2}$

The second and most prominent convergence line produced by the model extends southeastward from about $14^{\circ}$ to $18^{\circ} \mathrm{S}$. This line corresponds to the northeasterly morning glory. It is oriented $140^{\circ}-320^{\circ}$, while from the satellite imagery the northeasterly morning glory is oriented $144^{\circ}-324^{\circ}$. Taking into account the 30-min difference in time between the satellite image

\footnotetext{
${ }^{2}$ To determine these orientations, the satellite images and convergence plots were stretched appropriately so that the meridional distance and zonal distance were locally equal at $17^{\circ} \mathrm{S}$.
}

and the forecast time, the inaccuracy in the forecasted position is only on the order of $20 \mathrm{~km}$. In the model, the convergence line bends sharply southward at the coastline. This is in reasonable agreement with the satellite image, which shows cloud extending southward from the southern end of the northeasterly morning glory roll clouds.

The third convergence line is oriented roughly eastwest along $18.5^{\circ}-19.5^{\circ} \mathrm{S}$, and corresponds to the southerly morning glory. This line is marked in the model by a strong southerly surge, as observed, but is located around $100 \mathrm{~km}$ too far south. The fourth significant convergence line developed by the model corresponds 
(a) 1600 EST on 28 September 2002

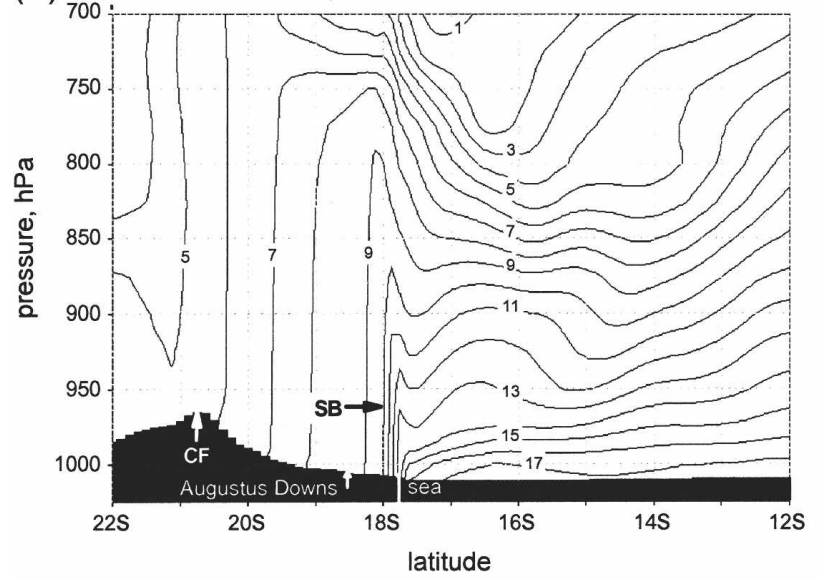

(c)

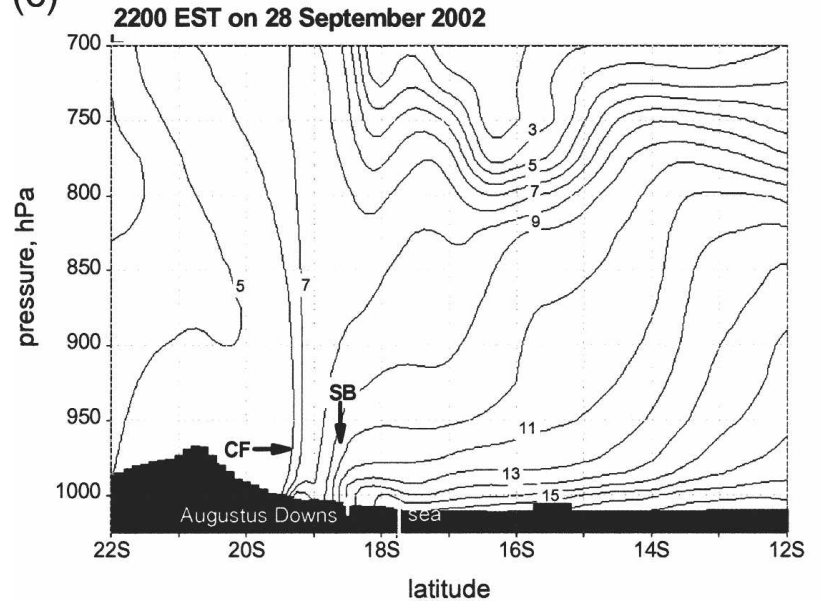

(b) 1900 EST on 28 September 2002

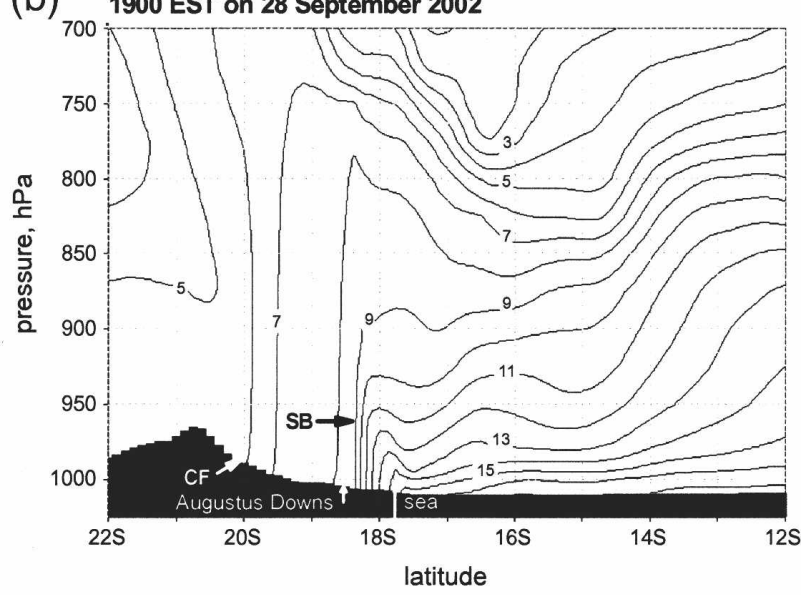

(d)

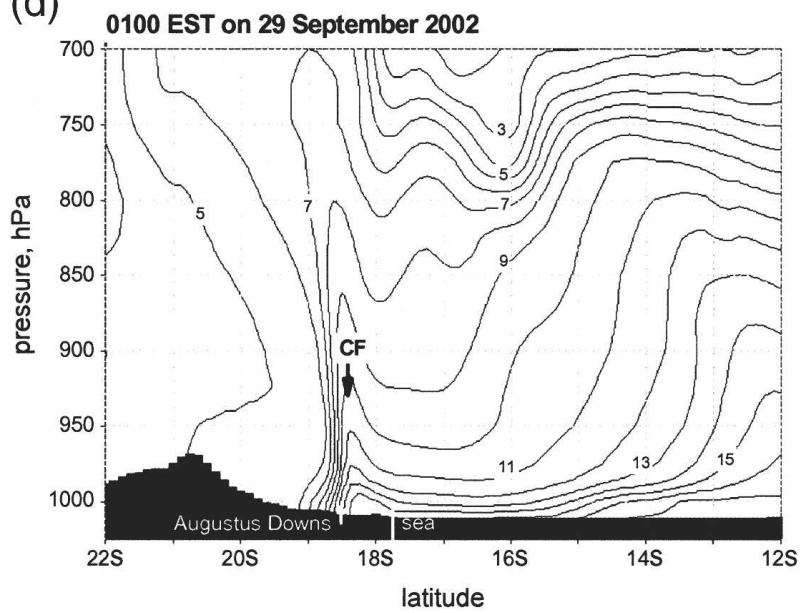

FIG. 5. Meridional cross sections of the mixing ratio (contour interval $1 \mathrm{~g} \mathrm{~kg}^{-1}$ ) for the case of the southerly disturbance on $28-29$ Sep, corresponding to the forecasts in Fig. 4. The vertical white line just north of $18^{\circ} \mathrm{S}$ on the abscissa marks the coastline. The arrow marks the location of Augustus Downs. The positions of the cold front and sea-breeze front to the south of the gulf are marked by CF and SB, respectively. In (d) the sea breeze has been overrun by the cold front and can no longer be identified.

to a relatively uniform cloudy area extending westward from the northeasterly morning glory between about $15^{\circ}$ and $17^{\circ} \mathrm{S}$ in the model and about $16^{\circ}$ and $17^{\circ} \mathrm{S}$ in the satellite imagery. Observations show that the passage of a northeasterly morning glory or an NACL is accompanied by a change in sign of the zonal component of near-surface wind (e.g., Goler et al. 2006). As before, the times of the wind changes at various AWS stations can be estimated from 3-hourly MesoLAPS output by linear interpolation between two output times with an accuracy of about $\pm 30 \mathrm{~min}$. Table 2 compares these times of passage with those observed at various AWSs across the network.

As in event 1, the predicted times of passage are later than those recorded at all stations and in this case range from $40 \mathrm{~min}$ to over $3 \mathrm{~h}$. Some of the differences in the times of passage may be a result of the error in the orientation of the convergence line in MesoLAPS that corresponds to the observed morning glory, which in turn may be a result of the model resolution. A much higher resolution simulation of this event using the fifth-generation Pennsylvania State UniversityNational Center for Atmospheric Research Mesoscale Model (MM5) with a 3-km horizontal grid shows considerable improvement in the prediction of this orientation (Thomsen and Smith 2006).

Although MesoLAPS captures an east-west-oriented band of convergence south of the gulf, the band remains almost stationary. Thus, on the basis of these forecasts, one would not have expected the occurrence of a southerly morning glory as observed. There are several possible reasons for this failure. One factor may be an inaccurate analysis of the convergence line in the initial conditions. As noted earlier, the analysis field tends to be relatively smooth because it is taken from a coarser-resolution model. The sharp features repre- 
(a)

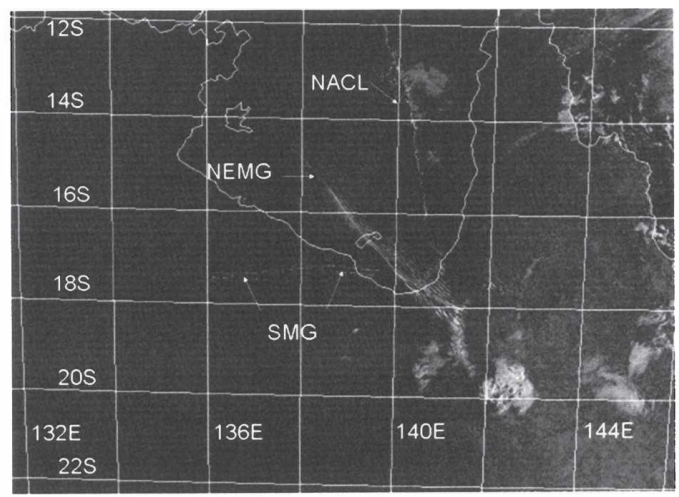

(b)

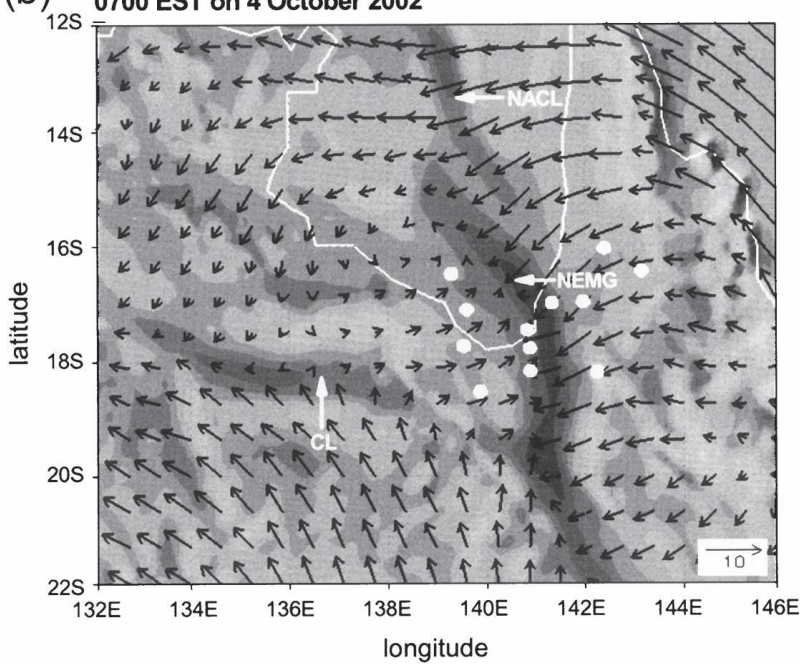

FIG. 6. (a) Visible GMS satellite image at 0632 EST 4 Oct 2002. Arrows indicate the northeasterly morning glory (NEMG), southerly morning glory (SMG), and NACL. (b) The 21-h MesoLAPS forecast of divergence (grayscale as in Fig. 2) and wind vectors at $995 \mathrm{hPa}$ valid at $0700 \mathrm{EST}$. The wind speed is proportional to the length of the arrows. The arrow in the lower-right corner of (b) corresponds to $10 \mathrm{~m} \mathrm{~s}^{-1}$. The white dots mark the positions of the AWSs. The positions of the convergence lines corresponding with the cold front, the NACL, and the NEMG are marked by CL, NACL, and NEMG, respectively.

senting convergence lines develop only during the forecast and they may develop in the wrong location. Another factor in this case may have been the relative weakness of the front compared with the event of 28-29 September. One measure of the strength of a front is the magnitude of the relative vorticity. A comparison of meridional cross sections of the relative vorticity for both the event of the 28-29 September (Fig. 7, top panels) and the event of the 4 October (Fig. 7, bottom panels) corroborates this hypothesis. In each case the left panels are for two model output times before the southerly disturbance passed the southernmost AWS of the network and the right panels are for one output time after the passage. Note that there is a much sharper and more distinctive front in the case of 28-29 September than in the case of 4 October. Moreover, the front in the latter case remains almost stationary at pressures lower than about $940 \mathrm{hPa}$. In this case the problem does not appear to reside in the model resolution: the MM5 simulation referred to above, with initial conditions taken from the European Centre for Medium-Range Weather Forecasts analysis, failed also to capture the southerly morning glory on this day.

\section{c. Event 3: 8-9 October 2002}

Of those observed during GLEX, this event had the most complex structure with three sets of morning glory cloud lines: one propagating from the northeast, one from the south, and one from the southeast, as well as an NACL over the northeastern part of the gulf. The synoptic situation was similar to that on 28-29 September, but the airmass change did not reach quite so far north. Data from an instrumented research aircraft are available for this event, including a flight leg at about $250 \mathrm{~m}$ underneath and perpendicular to the welldeveloped southeasterly cloud line, and an overflight in the region where the three disturbances were interacting over the southern gulf (Smith et al. 2006).

Figure 8 shows the satellite image at 0832 EST 9 October and the corresponding low-level divergence and winds at $995 \mathrm{hPa}$ at $0700 \mathrm{EST}$ on this day. The divergence pattern shows two significant bands of strong convergence: one oriented north-northwest to south-southeast and corresponding approximately with the NACL over the northern gulf and the other lying inland from the southern gulf coast. As in event 1, the southeasterlies on the poleward side of the southerly band are associated with a strong ridge over the continent, while the northerlies on the equatorward side are a result of the sea breeze of the previous day. The sharp increase in southeasterly winds at the eastern end of this band is presumably responsible for the generation of the southeasterly morning glory. In this case the times of passage of the southerly lines correspond well $( \pm 1 \mathrm{~h})$ with the observed times through the AWS network.

The satellite image in Fig. 8a shows that the northeasterly morning glory has an orientation of $150^{\circ}-330^{\circ}$ between $15^{\circ}$ and $17^{\circ} \mathrm{S}$, which is very close to the orientation of the convergence line in the model $\left(155^{\circ}-335^{\circ}\right)$. Taking into account the 30-min difference in time between the satellite image and the forecast time, the inaccuracy in the forecasted position is on the order of $40 \mathrm{~km}$. There is a second convergence line in the forecast, oriented close to north-south and lying just off the northwest coast of the peninsula. The position and ori- 
TABLE 2. Times (EST) of passage of the northeasterly morning glory recorded at the AWSs on 4 Oct and time of wind changes derived from the MesoLAPS forecasts.

\begin{tabular}{|c|c|c|c|}
\hline \multirow[b]{2}{*}{ Station } & \multicolumn{2}{|c|}{ Northeasterly morning glory } & \multirow{2}{*}{$\frac{\text { Time diff }}{t(\text { MesoLAPS })-t(\mathrm{AWS})}$} \\
\hline & AWS & MesoLAPS & \\
\hline Highbury & 22003 Oct & 22003 Oct & 0 \\
\hline Dunbar & 22503 Oct & Unclear & - \\
\hline Vanrook & 0150 & 0345 & $1 \mathrm{~h} 55 \mathrm{~min}$ \\
\hline Delta Downs & 0350 & 0430 & $40 \mathrm{~min}$ \\
\hline Karumba & 0510 & 0715 & $2 \mathrm{~h} 5 \mathrm{~min}$ \\
\hline Magowra & 0540 & 0730 & $1 \mathrm{~h} 50 \mathrm{~min}$ \\
\hline Croydon & No data & 21003 Oct & - \\
\hline Milgarra & 0620 & 0745 & $1 \mathrm{~h} 25 \mathrm{~min}$ \\
\hline Mornington Island & 0650 & 1000 & $3 \mathrm{~h} 10 \mathrm{~min}$ \\
\hline Sweers Island & 0730 & 1015 & $2 \mathrm{~h} 45 \mathrm{~min}$ \\
\hline Burketown & 0840 & 1100 & $2 \mathrm{~h} 20 \mathrm{~min}$ \\
\hline Augustus Downs & 1000 & 1045 & $45 \mathrm{~min}$ \\
\hline
\end{tabular}

entation of this line correspond approximately with those of the NACL in Fig. 8b.

The meridional cross sections of the virtual potential temperature and water vapor mixing ratio have structures very similar to those of 28-29 September shown in Fig. 4 and a brief description will suffice. As in this earlier case, the moisture fields on 9 October contain a narrow band of strong gradient at low levels. The strongest gradient lay at about $19.1^{\circ} \mathrm{S}$ at $0100 \mathrm{EST}$ and progressed steadily northward, reaching about $17.5^{\circ} \mathrm{S}$ by 1000 EST. It passed Augustus Downs at about 0400 EST, which is $3 \mathrm{~h}$ earlier than the recorded time of passage there at $0710 \mathrm{EST}$. In comparison with the moisture structure, the horizontal temperature gradient in the lowest $500 \mathrm{~m}$ was not very pronounced in this event in the region of Augustus Downs, which is consistent with the aircraft observations described by Smith et al. (2006).

For this event we carried out pilot balloon and radiosonde soundings at Karumba, which lies in the normally data-sparse region of the southern gulf. Figures $9 \mathrm{a}$ and $9 \mathrm{~b}$ show a comparison of the low-level wind fields observed at two times (1630 EST 8 September and 0240 EST 9 September) and those from the model at the closest forecast times (1600 EST 8 September and 0100 EST 9 September). MesoLAPS captures the wind speed and direction remarkably well with one important exception: it underpredicts the strength of the onshore branch of the sea breeze below about $950 \mathrm{hPa}$. Figures $9 \mathrm{c}$ and $9 \mathrm{~d}$ show a comparison of the potential temperature structure observed at 1635 EST 8 September and 0016 EST 9 September and those from the model at the closest forecast times (1600 and 0100 EST, respectively). Both forecast profiles show good agreement with the observed profiles above the boundary layer, but MesoLAPS does not capture the details of the boundary layer, including the sharp inversion at the top and the stable layers below. Instead it greatly smoothes these features. This would have implications for a correct representation of the morning glory waveguide and may explain why the nocturnal lowlevel jet is not well captured in the wind fields shown in Figs. 9a and 9b.

\section{d. Summary of the case studies}

The foregoing case studies suggest that MesoLAPS has significant skill in forecasting the occurrence of convergence lines in the gulf region, but it does not capture all of the lines. In all three events, the predicted times of passage of the convergence lines were mostly within an hour or two of the observed times, with a tendency to be late; in events 2 and 3 , where satellite imagery was available for comparison, the model predicted the orientation of the lines with considerable accuracy. The horizontal resolution of the model $(12.5 \mathrm{~km})$ is too coarse to represent the wavelike structures that develop at the leading edge of the lines, but the model does indicate a separation of a borelike disturbance from an airmass change in events 1 and 3 as observed.

\section{Other events during GLEX}

During the 45-day period of GLEX (10 September24 October 2002), NACLs were observed on 32 days, northeasterly morning glories were observed on 33 days, and southerly morning glories on 12 days. The occurrence of an NACL was determined primarily from an examination of satellite imagery. In one or two events the cloud line was not very distinct, but in the majority of cases it was clearly identifiable. The occurrence of northeasterly and southerly morning glories was determined both from satellite imagery and from 
(a)

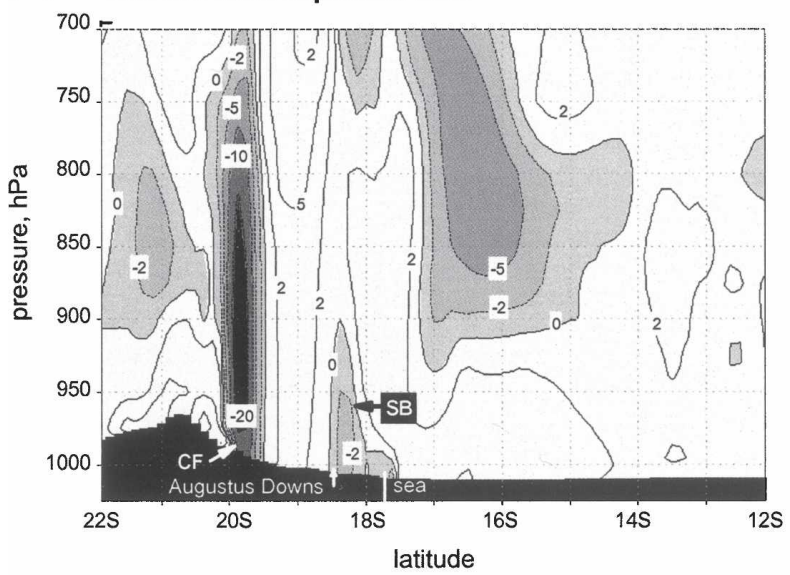

(c)

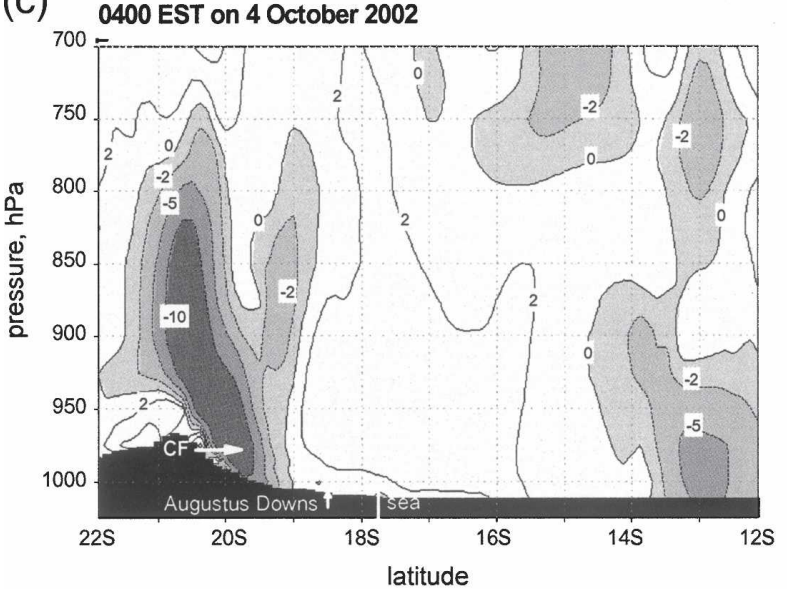

(b)

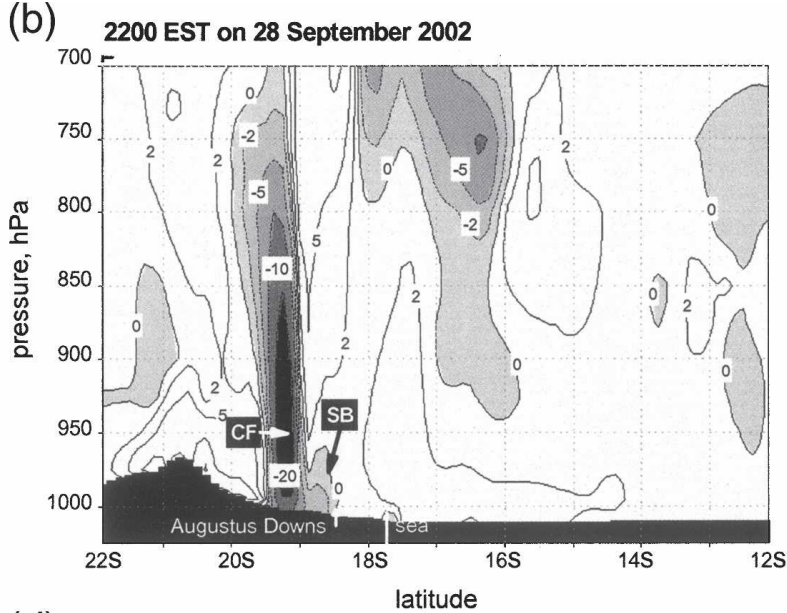

(d)

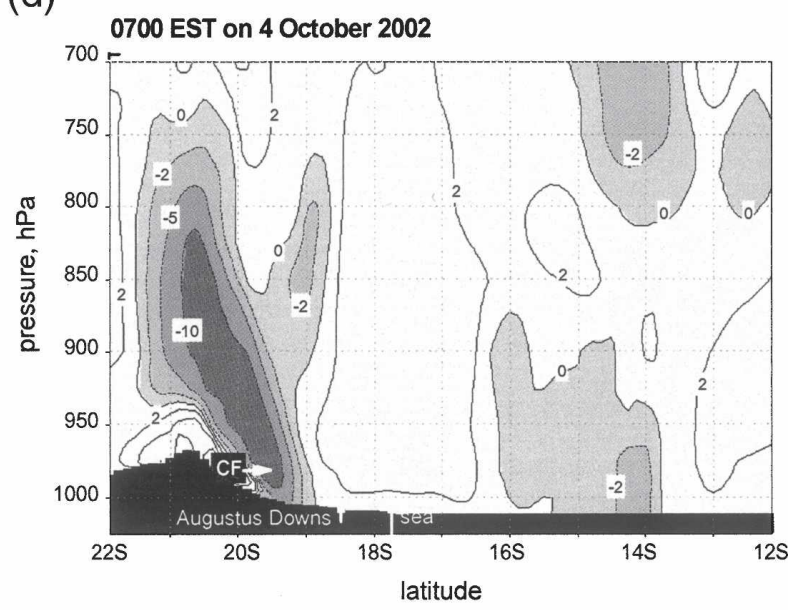

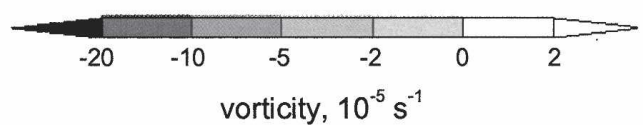

FIG. 7. Meridional cross sections of the relative vorticity (grayscale, $\times 10^{-5} \mathrm{~s}^{-1}$ ) for (a) 1900 and (b) 2200 EST 28 Sep, and (c) 0400 and (d) 0700 EST 4 Oct. In the 28 Sep case the southerly disturbance passed the southernmost AWS of the network, Augustus Downs, at 2115 EST and in the 4 Oct case it passed there at 0420 EST. The vertical white line just north of $18^{\circ} \mathrm{S}$ on the abscissa marks the coastline. The arrow marks the location of Augustus Downs. The positions of the cold front and sea-breeze front to the south of the gulf are marked by $\mathrm{CF}$ and SB, respectively. On 4 Oct, the times are later and the sea breeze is absent.

the existence of wind and pressure signatures at AWS stations in the southeastern gulf region. Not all of these disturbances were clearly marked by cloud, the occurrence of which depends on the presence of sufficient low-level moisture. In some cases the disturbances crossed the instrument network before daybreak so that visible satellite imagery was unavailable before their demise. Only the more extensive cloud lines show up at all in the infrared imagery, but the detail cannot be seen.

We examine now the performance of MesoLAPS for the entire 44-day period between 11 September and 24 October for which both the forecasts and some surface station data were available. First, we discuss the criteria used for a correct forecast of each type of disturbance. The criteria we adopted for a correct forecast of a northeasterly morning glory or an NACL are the existence of a strip of convergence moving off the peninsula in the late afternoon or early evening with magnitude of greater than $5.0 \times 10^{-5} \mathrm{~s}^{-1}$ at $\sigma=0.995$, followed by strong $\left(>7.5 \mathrm{~m} \mathrm{~s}^{-1}\right)$ easterly or northeasterly winds to the east at the same model level. In the case of a southerly morning glory, the strip of convergence is oriented in the east-west to northwest-southeast sector and it moves from the south or southwest during the evening to reach the southern gulf coastline overnight or shortly after daybreak (within $2 \mathrm{~h}$ of the observed time). The criterion for the convergence was obtained by trial and 
(a)

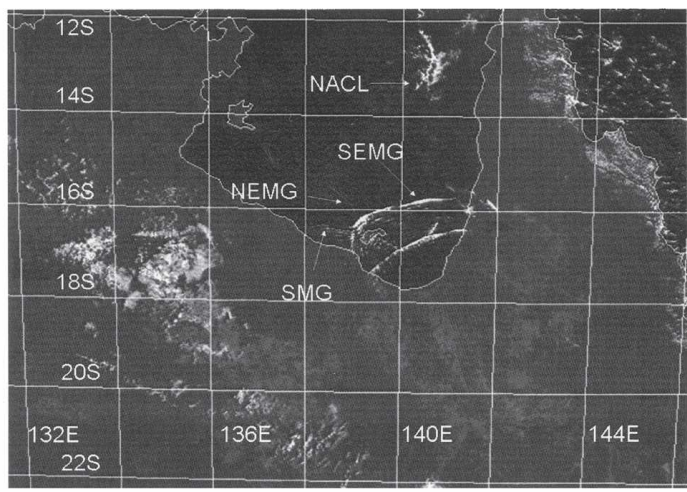

(b)

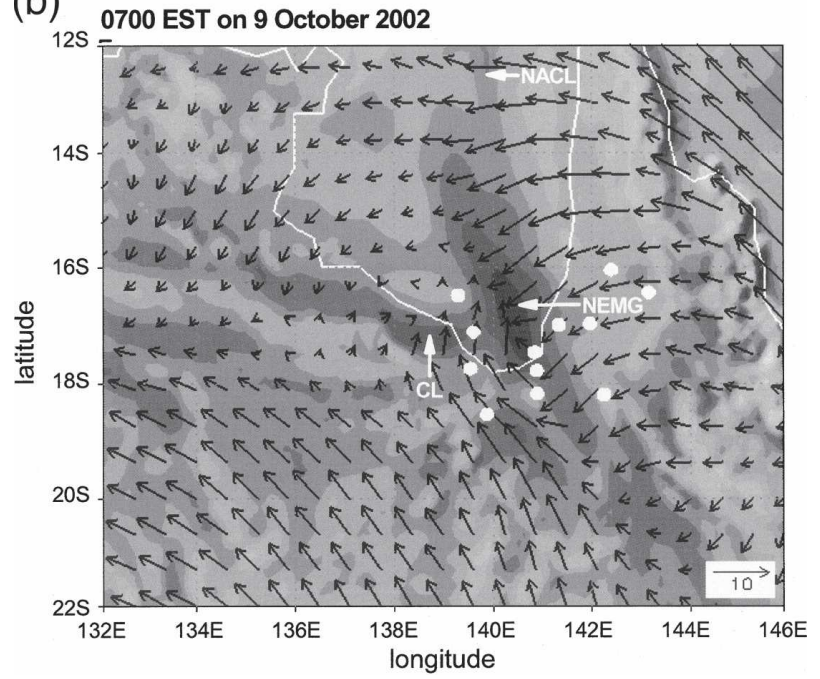

FIG. 8. (a) Visible GMS satellite image valid at 0832 EST 9 Oct 2002. Arrows indicate the NEMG, SMG, SEMG, and NACL. (b) Horizontal divergence (grayscale as in Fig. 2) and low-level winds at $995 \mathrm{hPa}$ over the gulf at $0700 \mathrm{EST}$ are shown. The wind speed is proportional to the length of the arrows. The arrow in the lower-right corner of (b) corresponds to $10 \mathrm{~m} \mathrm{~s}^{-1}$. The white dots mark the positions of the AWSs. The positions of the convergence lines corresponding to the SMG, the NACL, and the NEMG are marked by CL, NACL, and NEMG, respectively. The model does not distinguish between the southeasterly and southerly morning glories on this day.

error: larger values tend to define bands of convergence that are too broad, while smaller values may miss some lines. The winds were generally light preceding the passage of the lines. For northeasterly morning glories, the strip of convergence was required to reach the southern gulf region within an hour or two of the observed time. In many cases MesoLAPS produces a single line extending across much of the gulf, although in some cases one can distinguish between two parts of the line: one presumably indicating a northeasterly morning glory and the other an NACL.

On a few occasions the model produced a line of enhanced convergence over the southeastern part of the gulf in situations where there were strong south- easterly winds. Observations suggest that northeasterly morning glories do not occur in such conditions and we interpreted such cases as forecasts of nonevents. The idealized numerical model study carried out by Smith and Noonan (1998) showed that a sharp wind change from the northeast does not occur in the southeastern part of the gulf when the broadscale wind direction is from the southeast.

In the case of southerly morning glories, the closer the convergence line approaches the gulf before sunrise, the more likely is the occurrence of a southerly disturbance in reality. In all cases during the 44-day period when southerly disturbances were observed, MesoLAPS indicates a convergence line south of the gulf.

The results of the analysis are summarized in Table 3 for the three types of disturbances: northeasterly morning glories, NACLs, and southerly morning glories. The first row in the table shows the number of occasions when a disturbance of a particular type was observed and forecasted by MesoLAPS. The second row shows the number of days when no disturbance was observed and when none would have been anticipated from the MesoLAPS forecast. In each case these would be interpreted as correct forecasts, the percentage of which are given in the third row. About $84 \%$ of forecasts of northeasterly morning glories and southerly morning glories or of their nonoccurrence were correct, while the corresponding percentage for NACLs was about $66 \%$, an indication of the considerable overall skill of the model. The figures for southerly morning glories include the dryline passage on 24 October that was correctly forecasted. The fourth row in Table 3 shows the number of occasions on which a disturbance of a particular type was observed, but not forecasted, and the fifth row shows the number of occasions on which a disturbance was forecasted, but not observed. The percentages of these incorrect forecasts are given in the last column of the table. Row 4, in particular, suggests that all three types of disturbances tended to be underforecasted. About $16 \%$ of the northeasterly morning glories and about $34 \%$ of the NACL events that occurred were not forecasted. From 11 southerly events, 6 were forecasted and 5 were not. Three of these were classified as minor events in Smith et al. (2006; events 3, 7, and 10 in their Table 1), the other two (events 2 and 5) as major events. These percentages are, of course, related to the chosen criteria and small differences could be expected in the numbers if these criteria were varied. Indeed, there were one or two forecasts that could be regarded as borderline cases based on these criteria.

Clearly, MesoLAPS performs better for disturbances moving from the northeast than for those moving from 

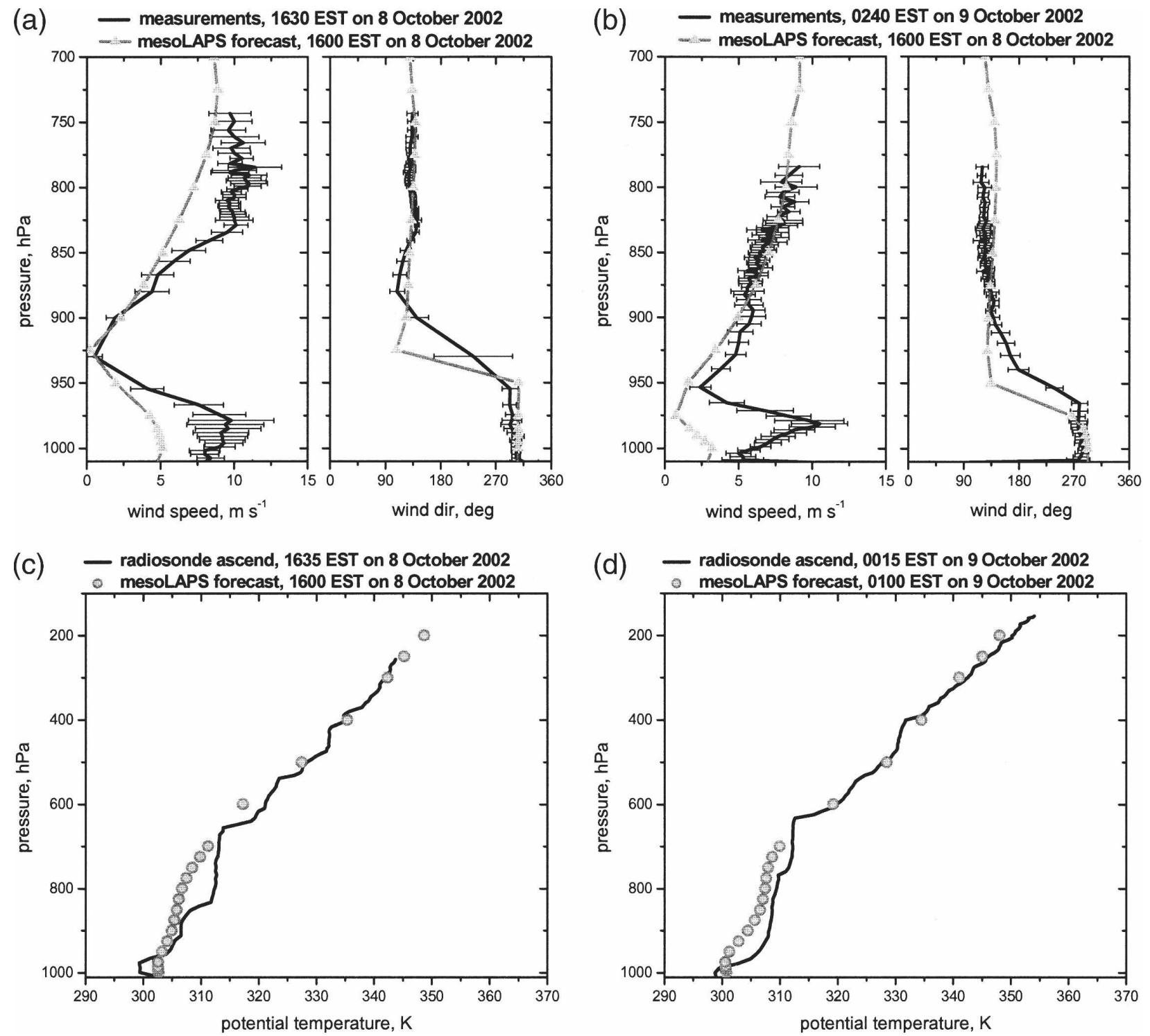

FIG. 9. Comparison of model forecasts of the low-level vertical wind structure with pilot balloon observations at Karumba at (a) 1600 EST 8 Oct and (b) 0100 EST 9 Oct, and with radiosonde observations there at (c) 1635 EST 8 Oct and (d) 0015 EST 9 Oct 2002. Estimates of the errors in determining the winds in (a) and (b) are indicated by horizontal bars.

the south. The reason is probably because the northeasterly lines form during the forecast as a result of the mesoscale circulations (i.e., sea breezes) over Cape York Peninsula and are therefore less sensitive to the details of the initial conditions than southerly disturbances. Even so, accurate forecasts of northeasterly disturbances requires a reasonably accurate depiction of the broadscale flow in the region. In contrast, the accurate prediction of southerly morning glories is likely to be more dependent on an accurate analysis of the initial position of the line over the continent, where the data are relatively sparse.

To obtain a measure of the accuracy of the forecasts of northeasterly morning glories and the NACL, we compared the orientation and position of the forecasted lines of maximum horizontal convergence at $975 \mathrm{hPa}$ with those of cloud lines seen in visible satellite imagery at $0630 \mathrm{EST}$, or in one case at $2230 \mathrm{EST}$. We examined 11 occasions on which northeasterly morning glories were visible (in many cases the disturbances had moved over land and the clouds were presumed to have decayed by the time the first visible image was available), and in nine of these cases NACLs were seen as well. In five cases the morning glory line in the satellite image had a bend at between $16^{\circ}$ and $17^{\circ} \mathrm{S}$. In four of these cases the forecast showed a bend also and in these cases 
TABLE 3. Summary of MesoLAPS forecasts for all events during the period $11 \mathrm{Sep}-24$ Oct. The first two rows show the matrix structure of the data for the three types of disturbance.

\begin{tabular}{lcc}
\hline \hline $\begin{array}{c}\text { Disturbance } \\
\text { Correct } \\
\text { forecasts }(\%)\end{array}$ & $\begin{array}{c}\text { Observed, forecasted } \\
\text { forecasted }\end{array}$ & $\begin{array}{c}\text { Observed, not forecasted } \\
\text { not forecasted }\end{array}$ \\
\hline NEMG & 26 & 7 \\
84 & 0 & 11 \\
NACL & 18 & 13 \\
66 & 2 & 11 \\
SMG & 6 & 5 \\
84 & 2 & 31 \\
\hline
\end{tabular}

we compared the orientation north and south of the bend. The orientation of the morning glory in the model averaged over all 11 cases was within a degree of the average of that observed with a standard deviation of $6^{\circ}$. South of the bend the agreement was not quite so good; the average error being $6^{\circ}$ with a standard deviation of $11^{\circ}$. The statistics for the NACL were similar: in seven cases, the average orientation in the model was within a degree of the average of that observed with a standard deviation of $6^{\circ}$. In two cases there was no obvious convergence line corresponding to the NACL. The timing of the morning glory convergence line in the model was within an average of $80 \mathrm{~min}$ of that observed, with a standard deviation of $100 \mathrm{~min}$. In nine cases the line in the model was too late and in two it was too early, but by less than $1 \mathrm{~h}$. In over half the cases the time was within an hour of that observed, while in three cases it was over $3 \mathrm{~h}$ late, the worst case being $4.5 \mathrm{~h}$ late. In five of the seven NACL cases for which the model forecasted a convergence line, the timing was correct to within an hour and always late. In the two other cases, it was late by 1.5 and $3 \mathrm{~h}$. We did not extend the foregoing analysis to southerly morning glories as satellite imagery was unavailable in most of the six cases that were forecasted by the model.

\section{The similarity between northeasterly and southerly morning glory genesis}

It is enlightening to compare zonal-height cross sections of potential temperature and horizontal wind during the formation of northeasterly morning glories with similar sequences of meridional-height cross sections during the formation of southerly morning glories. Figure 10 shows two such pairs of cross sections: one for the northeasterly disturbance on 4 October and the other for the southerly disturbance on 28-29 September. The bottom panels in Fig. 10 show the cross section along $16.5^{\circ} \mathrm{S}$ at $0100 \mathrm{EST} 4$ October, shortly before the sea breezes from the east and west coasts of the peninsula collide, and at 0700 EST, long after the collision.
In Fig. 10c the sea-breeze fronts are clearly visible as zones of large horizontal temperature gradients inland from each side of the coast with a sharp wind change across them. By 0700 EST (Fig. 10d), the convergence line that forms following the collision of the two sea breezes has moved westward over the gulf.

The top panels in Fig. 10 show the cross sections along $140^{\circ} \mathrm{E}$ at $2200 \mathrm{EST} 28$ September and at 0400 EST 29 September. At 2200 EST (Fig. 10a), the warmest air lies within the trough centered at about $19^{\circ} \mathrm{S}$. A cold front lies to the south of the trough with moderately strong southeasterly to south-southeasterly winds below a height corresponding to about $800 \mathrm{hPa}$. The winds in the cooler air immediately north of the trough are northerly below a height corresponding to about $950 \mathrm{hPa}$ and are a manifestation of the shallow sea breeze from the southern gulf coast. The isentropes show that the cooler air mass to the south of the trough is much deeper than that to the north. As time proceeds, the front moves northward and collides with and overruns the sea-breeze air, just as the cooler and deeper east coast sea-breeze air overruns the west coast sea breeze in the case of 4 October. On both $28 \mathrm{Sep}$ tember and 4 October, the respective air masses have similar depths. Moreover, in both cases the deeper cool air mass overruns a shallower one, which itself acts like a stable layer to the former. Thus, the broad-scale generation mechanisms of northeasterly and southerly morning glories are essentially the same with a deeper cool flow overrunning a shallower one (Goler and Reeder 2004). The high-resolution numerical simulations of these two events described by Thomsen and Smith (2006) support the foregoing picture.

\section{Conceptual model for southerly disturbances}

The analyses in section 5 suggest a conceptual model for the generation of southerly morning glories as illustrated in Fig. 11. The MesoLAPS simulations indicate that the inland heat trough is a prominent feature of the synoptic environment in which southerly morning glory bore waves are generated at night (see Fig. 11). The inland trough coincides with the highest mixed layer temperature and the deepest mixed layer. During the early evening over the land, the generation of convective turbulence ceases and the surface layer begins to stabilize due to radiative cooling. With the reduced friction, a nocturnal low-level jet forms, predominantly on the southern side of the trough, where the daytime pressure gradients are strongest. The jet has an ageostrophic wind component into the trough that leads to low-level convergence and frontogenesis on the southern side of the trough. The MesoLAPS simulations suggest that the convergence and frontogenesis 
(a)

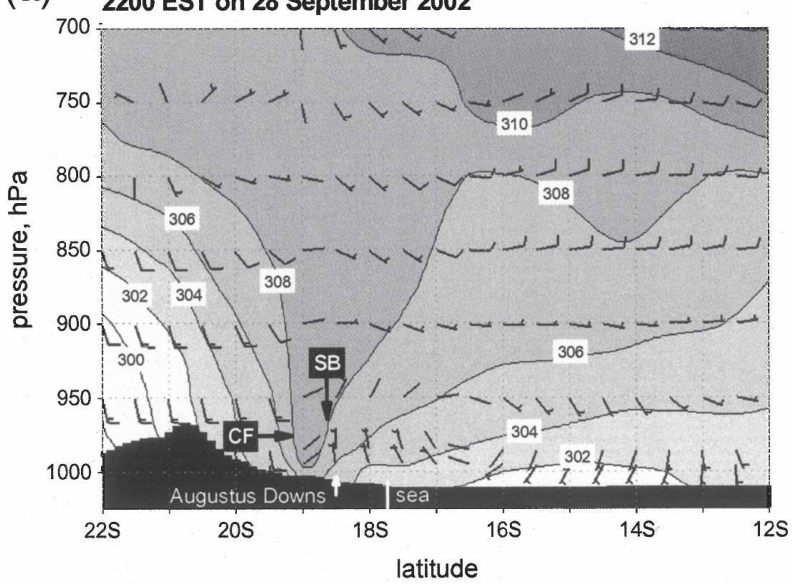

(c) 0100 EST on 4 October 2002

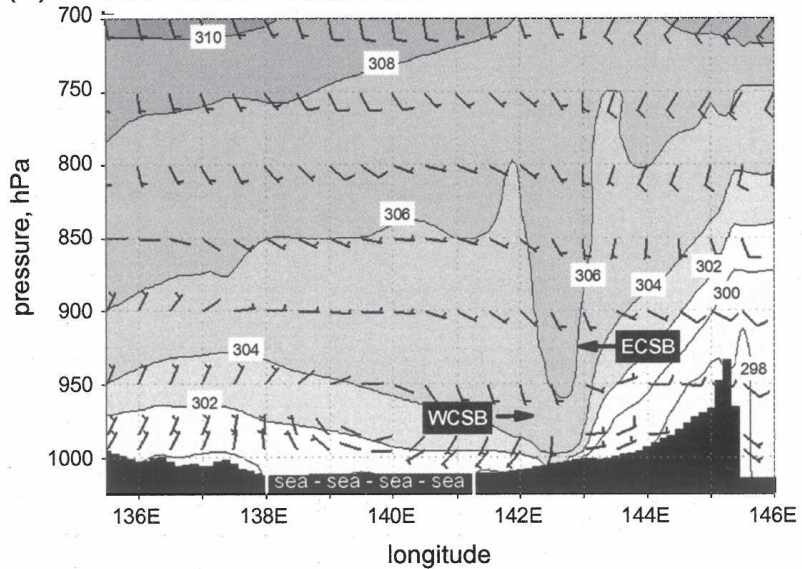

(b)

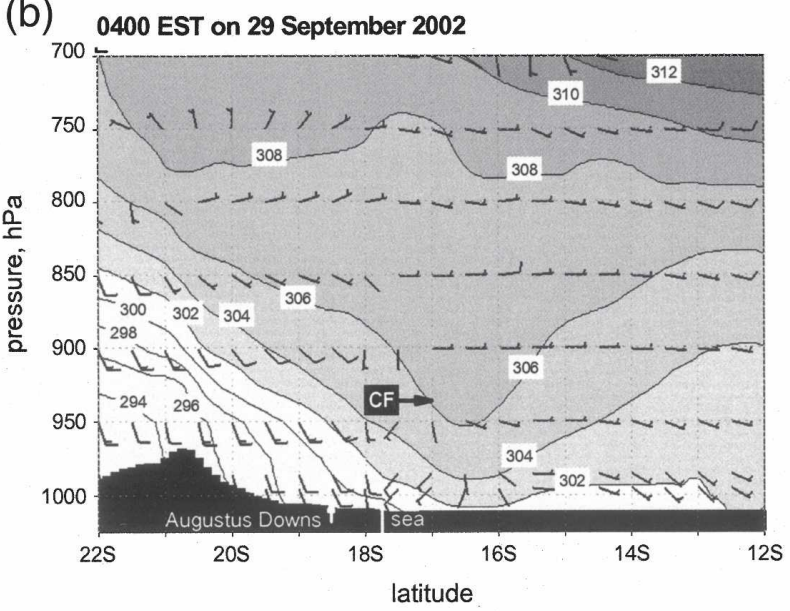

(d)

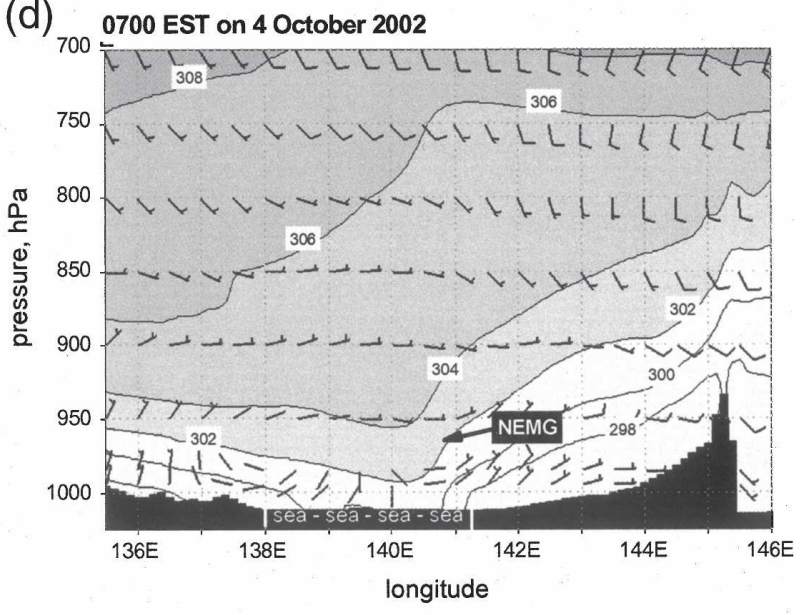

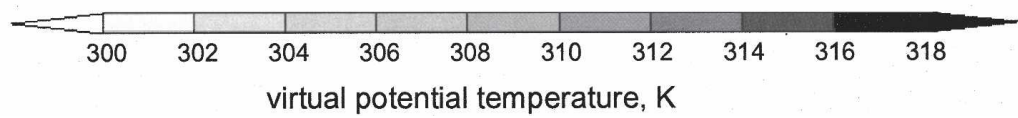

FIG. 10. (top) South-north cross section for the southerly disturbance on 28-29 Sep and (bottom) east-west cross section for the northeasterly disturbance of 4 Oct of virtual potential temperature (grayscale, K) and horizontal wind (wind barbs): (a) 2200 EST 28 Sep, (b) 0400 EST 29 Sep, and (c) 0100 and (d) 0700 EST 4 Oct. The positions of the cold front and sea-breeze front to the south of the gulf are marked by CF and SB in (a) and (b). The positions of the east and west coast sea-breeze fronts over the peninsula are marked by ECSB and WCSB in (c), and the position of the northeasterly morning glory is marked by NEMG in (d).

produce a shallow cold front moving from the south, which runs into the sea breeze to the north. The predictions of the formation of the jet, the nocturnal frontogenesis, and the movement of front will depend on how well frictional effects are represented in the model.

We cannot say whether the heat trough is absolutely necessary for bore formation. However, we believe that essential ingredients are the meridional pressure and temperature gradients on the northern side of the high and diurnally varying mixing. It is the strength of the pressure gradient and the vigor of the mixing that determine the strength of the low-level convergence at night and the strength of the temperature gradient that influences the rate of nocturnal frontogenesis. The presence of the heat trough will strengthen both the temperature and pressure gradients.

Once the cold front has re-formed, ${ }^{3}$ there appear to be two plausible scenarios as suggested by the numerical simulations of Haase and Smith (1989). Both scenarios assume that the cold front has the character of a gravity current when it encounters the shallower decaying sea breeze approaching on the northern side of the trough. This assumption finds

\footnotetext{
${ }^{3}$ Frontolysis normally occurs during the daytime because of the effects of vertical mixing (Smith et al. 1995; Reeder and Tory 2005).
} 


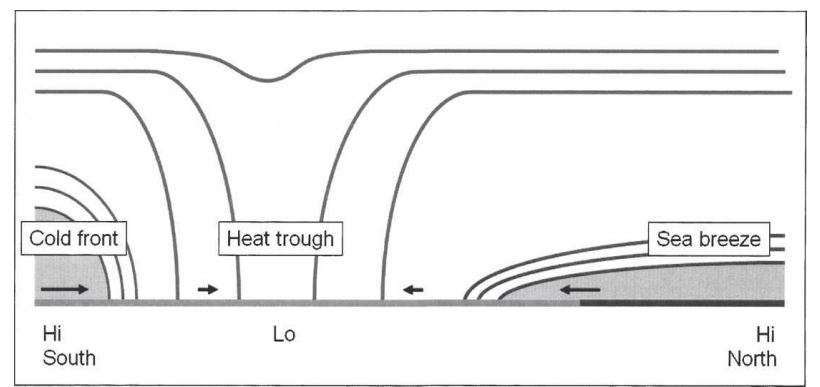

FIG. 11. Conceptual model for the inland trough and its tendency to spawn southerly morning glory bore waves at night. A meridional cross section of the isentropes (solid lines) is shown with the coldest potential temperatures shaded and the component of low-level airflow indicated by arrows. Frontogenesis occurs to the south of the heat trough after sunset. The cold front moves equatorward and collides with the sea breeze to the north of the trough. The sea-breeze air provides a surface-based stable layer and a deep layer of well-mixed air from the continent lies over the sea breeze. Together these form a waveguide on which the bore waves can propagate.

some support in recent high-resolution simulations of the event of 28-29 September (event 1) by Thomsen and Smith (2006). If the stable layer provided by the sea breeze is deep enough and strong enough, the cold front would generate a northward-moving bore wave that runs ahead of the front itself, on the stable layer. On the other hand, if the sea breeze is too shallow or the stability too weak, the cold front becomes transformed into a borelike disturbance. In the former case, the result would be a double-line structure with a bore disturbance running ahead of an airmass change as in the case of 28-29 September. In the latter case, only a single undular disturbance would be expected. While the resolution of MesoLAPS is much too coarse $(12 \mathrm{~km})$ to capture the details of this process, the high-resolution simulations by Thomsen and Smith do show the transformation to a propagating disturbance after the collision in this case and also in the case of the northeasterly morning glory of 4 October.

\section{Conclusions}

This study is the first time that it has been possible to verify the performance of MesoLAPS using high temporal resolution surface data and the first time at all that predictions of southerly disturbances have been verified. The analyses show that with appropriate interpretation, it is possible to make skillful forecasts of the different types of convergence lines that form in the Gulf of Carpentaria region of northern Australia using MesoLAPS. During the 44-day period between 11 Sep- tember and 24 October, about $85 \%$ of the occurrences or nonoccurrences of northeasterly and southerly morning glories were correctly forecasted, compared with about $65 \%$ for NACLs. All three types of disturbance tended to be underforecasted by the model, but the predictions of the occurrence of the betterdeveloped disturbances were mostly very good. The predicted orientation of the morning glory cloud lines and the NACL were acceptable with a standard deviation error of $6^{\circ}$ for both types of line. In about $50 \%$ of the cases, the times of passage were within an hour of those observed and there was a marked tendency for the predicted lines to be late. MesoLAPS usually shows light winds at low levels ahead of the convergence lines with a sharp increase in wind speed behind the lines as is observed.

The predictions of the convergence lines associated with northeasterly morning glories and the NACL are generally superior to those of lines moving from the south. We attribute this superiority to the fact that these lines form during the forecast as a result of the sea breezes over Cape York Peninsula and are therefore less sensitive to the details of the initial conditions, although they depend, of course, on a reasonably accurate depiction of the broadscale flow in the region. In contrast, the accurate prediction of southerly morning glories is more dependent on an accurate analysis of the initial position of the line over the continent, where the data are relatively sparse.

Vertical cross sections of moisture in the three events examined in detail show a strong meridional gradient on the northern side of the inland trough. This moisture gradient explains the observed dryline, which the model shows to mark the maximum inland penetration of the sea breeze over northern Australia.

A sequence of vertical cross sections of winds and virtual potential temperature in the zonal direction for northeasterly morning glories and in the meridional direction for southerly morning glories shows that the generation mechanisms of the two types of disturbances have striking similarities. These cross sections indicate that the development of a shallow nocturnal cold front south of the inland trough in the southerly case is analogous to the development of the east coast sea-breeze front in the northeasterly case. In the former case, the cold front collides with and overruns the shallower, decaying sea breeze from the southern gulf coast, while in the latter case the east coast sea-breeze front over the Cape York Peninsula collides with and overruns the shallower west coast sea breeze. In each case, the deeper disturbance acquires a borelike character.

These findings lead us to propose a conceptual model 
for the generation of southerly morning glories. The mixed layer is deepest in the inland trough south of the gulf and the mixed layer temperature in the trough is warmer than to the north and south. During the early evening the generation of convective turbulence over the land ceases and the surface layer begins to stabilize due to radiative cooling. With the reduced friction, a nocturnal low-level jet forms, predominantly on the southern side of the trough, where the daytime pressure gradients are strongest. The jet has an ageostrophic wind component into the trough that leads to low-level convergence and frontogenesis south of the trough. In this way, a shallow cold front forms and moves northward, subsequently colliding with the shallower, decaying sea breeze to the north of the trough. A northwardmoving borelike disturbance emerges from the collision and runs ahead of the front itself. This conceptual model is consistent with MesoLAPS predictions and all previous observations and modeling studies of which we are aware. It provides a synthesis of results that have emerged from previous studies and provides a physical basis for interpreting model predictions.

Acknowledgments. We thank the Australian Bureau of Meteorology for its support, especially the Queensland and Northern Territory Regional Offices and the Bureau of Meteorology Research Centre. We are grateful to the following participants from Monash University, University of British Columbia, Airborne Research Australia, and the University of Munich: Andrew Coutts, Rudi Gaissmaier, Robert Goler, Thomas Hamburger, Gabriel Kalotay, Carsten Kykal, Heinz Loesslein, Andreas Roepnack, Brian Seymour, Rosemary Seymour, Thomas Spengler, Hilbert Wendt, and Hongyan Zhu. We thank Ilona Nudelmann for her assistance with some of the analyses in section 4 and Noel Davidson from the Australian Bureau of Meteorology for his perceptive critique of the original manuscript. Funding for the experiment came from the Australian Bureau of Meteorology, the Australian Research Council, and the German Research Council (Deutsche Forschungsgemeinschaft).

\section{REFERENCES}

Clarke, R. H., 1984: Colliding sea-breezes and the creation of internal atmospheric bore waves: Two-dimensional numerical studies. Aust. Meteor. Mag., 32, 207-226.

— R. K. Smith, and D. G. Reid, 1981: The morning glory of the
Gulf of Carpentaria: An atmospheric undular bore. Mon. Wea. Rev., 109, 1733-1757.

Drosdowsky, W., G. J. Holland, and R. K. Smith, 1987: North Australian cloud lines. Mon. Wea. Rev., 115, 2645-2659.

Fels, S. B., and M. D. Schwarzkopf, 1975: The simplified exchange approximation: A new method for radiative transfer calculations. J. Atmos. Sci., 32, 1475-1488.

Goler, R. A., and M. J. Reeder, 2004: The generation of the morning glory. J. Atmos. Sci., 61, 1360-1376.

,-- R. K. Smith, S. Arnup, H. Richter, T. D. Keenan, P. May, and J. Hacker, 2006: Low-level convergence lines over the Gulf of Carpentaria. Part I: The North Australian cloud line. Mon. Wea. Rev., 134, 3092-3108.

Haase, S. P., and R. K. Smith, 1989: The numerical simulation of atmospheric gravity currents. Part II: Environments with stable layers. Geophys. Astrophys. Fluid Dyn., 46, 35-51.

Jackson, G. E., R. K. Smith, and T. Spengler, 2002: The prediction of low-level mesoscale convergence lines over northeastern Australia. Aust. Meteor. Mag., 51, 13-24.

Lacis, A. A., and J. E. Hansen, 1974: A parameterization for the absorption of solar radiation in the earth's atmosphere. $J$. Atmos. Sci., 31, 118-133.

Noonan, J. A., and R. K. Smith, 1986: Sea-breeze circulations over Cape York Peninsula and the generation of Gulf of Carpentaria cloud line disturbances. J. Atmos. Sci., 43, 1679-1693.

—, and —, 1987: The generation of North Australian cloud lines and the "morning glory." Aust. Meteor. Mag., 35, 31-45.

Puri, K., G. S. Dietachmayer, G. A. Mills, N. E. Davidson, R. A. Bowen, and L. W. Logan, 1998: The new BMRC Limited Area Prediction System, LAPS. Aust. Meteor. Mag., 47, 203 223.

Reeder, M. J., and R. K. Smith, 1998: Mesoscale meteorology. Meteorology of the Southern Hemisphere, Meteor. Monogr., No. 49, Amer. Meteor. Soc., 201-241.

_ and K. J. Tory, 2005: The effect of the continental boundary layer on the dynamics of fronts in a two-dimensional model of baroclinic instability. Part II: Surface heating and cooling. Quart. J. Roy. Meteor. Soc., 131, 2409-2429.

, R. K. Smith, R. Deslandes, N. J. Tapper, and G. A. Mills, 2000: Subtropical fronts observed during the 1996 Central Australian Fronts Experiment. Aust. Meteor. Mag., 49, 181200.

Smith, N. R., 1995: The BMRC ocean thermal analysis system. Aust. Meteor. Mag., 44, 93-110.

Smith, R. K., and J. A. Noonan, 1998: On the generation of lowlevel mesoscale convergence lines over northeastern Australia. Mon. Wea. Rev., 126, 167-185.

_ - M. J. Coughlan, and J. Evans-Lopez, 1986: Southerly nocturnal wind surges and bores in northeastern Australia. Mon. Wea. Rev., 114, 1501-1518.

—, M. J. Reeder, N. J. Tapper, and D. R. Christie, 1995: Central Australian cold fronts. Mon. Wea. Rev., 123, 19-38.

— _ _ P. May, and H. Richter, 2006: Low-level convergence lines over northeastern Australia. Part II: Southerly disturbances. Mon. Wea. Rev., 134, 3109-3124.

Thomsen, G., and R. K. Smith, 2006: Simulations of low-level convergence lines over northeastern Australia. Quart. J. Roy. Meteor. Soc., 132, 691-707. 